\title{
Las funciones académicas en las universidades argentinas: una mirada en perspectiva histórica
}

\section{Academic Functions at Argentine Universities: An Analysis from a Historical Perspective}

\author{
Carlos A. Zavaro Pérez \\ (D) https://orcid.org/0000-0003-3298-7383 \\ Universidad Nacional de La Plata, Argentina \\ Facultad de Ciencias Naturales y Museo \\ czavaro@fcnym.unlp.edu.ar
}

Resumen: Se analizan algunas particularidades de la profesión académica en las universidades argentinas bajo el supuesto de que la coyuntura política, económica y social ha constituido el escenario en el que se explicitan y diferencian las funciones universitarias y se han configurado las tradiciones. En este sentido se intenta reconstruir una trazabilidad en perspectiva histórica de los principales hitos que han impactado en la manera en que estas prácticas se objetivan.

Palabras clave: práctica académica; universidad; investigación; extensión; transferencia.

Abstract: Certain particularities of the academic profession in Argentine universities are analyzed on the assumption that the political, economic, and social situation has constituted a scenario in which university functions are made

Cómo CITAR: Zavaro Pérez, C. A. (2021). Las funciones académicas en las universidades argentinas: una mirada en perspectiva histórica. Secuencia (109), e1734. DoI: https://doi.org/10.18234/secuencia.v0i109.1734

c) Esta obra está protegida bajo una Licencia Creative Commons Atribución-NoComercial 4.0 Internacional. 
explicit and differentiated, and traditions have been shaped. In this respect, an attempt is made to reconstruct a traceability from a historical perspective of major milestones that have impacted the way these practices are objectified.

Keywords: academic practice; university; research; extension; transfer.

Recibido: 29 de marzo de 2019 Aceptado: 4 de noviembre de 2019

Publicado: 17 de febrero de 2021

\section{INTRODUCCIÓN}

$\mathrm{E}$ estatuto de gran parte de las universidades argentinas enuncia al menos tres objetivos vertebrales que sustentan la vida académica: la docencia, la investigación y la extensión. Estas funciones, compartidas con otras universidades de Latinoamérica y del mundo, parecieran impregnar el imaginario de aquellos que integran cada uno de sus claustros, aun cuando no siempre están claramente definidos los límites entre las mismas, ya sea por los modos en que las tradiciones disciplinares han ido configurando históricamente sus prácticas o por razones conceptuales e ideológicas respecto de la manera en que estas se objetivan en los diversos modos de habitar la universidad, siendo que tradiciones e imaginarios en torno a estas no son lo mismo. Como hipótesis de base, las primeras se han ido constituyendo en el marco de un hábitus que es reproducido y enseñado por quienes lo aprendieron de sus profesores a lo largo de su carrera, pero que es modelado por el contexto económico y político, transformándose en medio de un proceso en el que también se han ido transformando los imaginarios construidos en torno a la manera en que estas prácticas se explicitan.

Reconstruir cronológicamente el modo en que se han ido configurando las diversas funciones que conforman la profesión académica en las universidades argentinas, en relación con el contexto histórico, constituye el propósito de estas notas, atento a la posibilidad de recuperar una trazabilidad que dé cuenta de un proceso en el que diversas expresiones y colectivos entienden y explicitan su identidad, aun cuando esta constituya una categoría de análisis en disputa. 


\section{LA UNIVERSIDAD COLONIAL}

El origen de la universidad argentina se remonta al siglo XVII cuando en el año 1613 abre sus puertas el "Colegio Máximo" en una de las misiones jesuíticas de la provincia de Córdoba, con el propósito de otorgar a sus estudiantes (mayoritariamente religiosos de la orden y jóvenes laicos de las familias más influyentes) una educación de excelencia en teología y filosofía, aunque no es sino hasta 1621 que el papa Gregorio XV, en el uso de su investidura, le confiere la facultad de otorgar grados académicos, una decisión que fue ratificada por la corona española mediante cédula real rubricada por Felipe IV el 2 de febrero de 1622. El colegio jesuita ha sido considerado la piedra fundacional de la Universidad Nacional de Córdoba, única en el país durante casi dos siglos, hasta que en 1821 se fundó la Universidad de Buenos Aires y posteriormente la Universidad del Litoral (1889) y la Universidad de La Plata (1897), consideradas entre las más antiguas (véase cuadro 1) del país y del continente.

No es casual que en medio de una coyuntura regida por la corona española, la universidad argentina desde su origen hubiese estado enfrascada en consolidar un proyecto colonialista encaminado a garantizar la formación profesional y cultural de una clase hegemónica elitista y liberal que, tal como sostiene Lander (1998), fue concebida bajo el imaginario de sujetos blancos, masculinos, urbanos y cosmopolitas, destinados a ocupar los cargos decisorios en el país y a custodiar los intereses de la clase dominante como garante de los intereses económicos y políticos de la metrópolis.

Tanto la Universidad de Córdoba como la de Buenos Aires fueron nacionalizadas en 1856 y 1881 respectivamente, lo que condujo a la reforma de sus estatutos y a la apertura de nuevas carreras durante las presidencias de Domingo Faustino Sarmiento y de Nicolás Avellaneda, quien fuera posteriormente rector de la Universidad de Buenos Aires (UBA); asimismo, impulsó la ley homónima, sancionada a mediados de 1885 , durante el gobierno de Julio Argentino Roca. La ley fue reconocida como la primera ley universitaria y contribuyó a institucionalizar el perfil de las universidades nacionales de entonces (Córdoba y Buenos Aires) estableciendo la designación de autoridades por una asamblea universitaria de profesores, el nombramiento de profesores por parte del poder ejecutivo ad referéndum de una terna propuesta por la institución y la creación de un fondo universitario que le confería cierta autarquía.

En este contexto, el proyecto de país de la clase dominante se espejó en el proyecto institucional de las universidades y, en consecuencia, gran parte 
de sus egresados provenían de la carrera de abogacía, aunque paulatinamente fueron incorporándose perfiles relacionados con las ciencias económicas y humanísticas. Este modelo de universidad que, a pesar de las guerras independentistas continuaba colonizado por mandatos instalados desde el exterior, promovió el auge en años posteriores de otras carreras como agronomía, ingeniería forestal o veterinaria, probablemente en respuesta al modelo económico agroexportador (Mollis, 2009) de desarrollo que se consolidó y caracterizó a la economía argentina de fines del siglo xIx y principios del xx.

Durante ese periodo conviven en el país diversos modelos de universidad que a su vez reproducen algunos de los imperantes en las diversas instituciones europeas y norteamericanas, cuyas tradiciones y valores fueron amalgamándose con los formatos preexistentes como parte de un proceso de sincretismo en el que comienzan a urdirse tradiciones y formas de expresión de muy diversas profesiones, tanto en su estructura organizacional como en lo referente a aquellas actividades que han sido constitutivas de la identidad de las diversas subculturas o tribus académicas (Becher, 2001). Como resultado de este proceso se impuso una matriz humboldtiana -elitista por naturaleza- que está centrada en el prestigio que otorga a las instituciones la investigación y bajo la cual se promueve el desarrollo de algunos temas por sobre otros que son elegidos por catedráticos que "dominan" ciertas fracciones del conocimiento, aun cuando no necesariamente estos saberes sean considerados de interés para la sociedad (Villa Pacheco, 2005).

\section{LA REFORMA EN CONTEXTO}

El contexto sociopolítico que caracterizó la primera veintena del siglo xIx y en especial la primera presidencia de Yrigoyen y la coyuntura internacional, alentó la consolidación de un movimiento reformista que, en reclamo de la democratización de las aulas -a las que definían como infecundas-, impulsó uno de los hechos más trascendentales relacionados con la vida académica, aunque con un impacto regional.

La reforma constituyó un hito revolucionario y profundamente latinoamericanista y social, aunque ideológicamente heterogéneo con una amalgama de matices que sumó tanto las ideas de Ortega y Gasset como las influencias del incipiente movimiento obrero conformado por inmigrantes y anarquistas alentados por el reciente triunfo de la revolución rusa de 1917 
(Acevedo Tarazona, 2011). A pesar de las diferencias conceptuales e ideológicas, la reforma universitaria tuvo un denominador común: una férrea postura anticlerical, antimperialista (Tünnermann, 1998) y emancipadora que se replicó en toda la región, con posiciones cuasi insurrectas bajo el protagonismo de un alumnado que, apoyado por el partido socialista argentino, se constituyó en artífice de un cambio estructural que pretendía terminar con una autoridad universitaria fundada en el autoritarismo y no en la legitimidad y que estaba conformada por profesores dogmáticos que se oponían a la modificación de los planes de estudio y del reglamento por temor a perder el empleo.

La reforma universitaria inauguró un proceso de diagnóstico crítico hacia el interior de las universidades argentinas que convirtió al Manifiesto Liminar $^{1}$ en un documento de referencia profundamente democrático que contribuyó a sentar las bases del cogobierno (Acevedo Tarazona, 2011) como modelo de gestión político-académica y de la autonomía universitaria, en virtud de la cual comienzan a diferenciarse las particularidades que distinguen el espíritu, la esencia y las tradiciones de gran parte de las instituciones del país.

Entre las conquistas esgrimidas por las tradiciones reformistas, se incluye la modificación de los planes de estudio, la autonomía universitaria y la inclusión en la agenda política del debate en torno al rol social de las universidades, que ha sido entendido como fundamento y génesis de la extensión universitaria (Fresán Orozco, 2004), aun cuando el propio manifiesto -que encarna el espíritu de la Reforma- no sea explícito al respecto, centrando su proclama en la crítica de un sistema que es descrito como "refugio de los mediocres" y al que rotulan como decadente, anacrónico y fundado en el "derecho divino del profesorado universitario". El manifiesto además propone centrar el objeto de la enseñanza en la formación de sujetos críticos que no se sometan a los textos ni a las imposiciones de sus profesores.

${ }^{1}$ El Manifiesto Liminar constituyó el documento oficial que resume las demandas de la llamada "Reforma Universitaria" acontecida en la Universidad Nacional de Córdoba (Argentina) el 21 de junio de 1918. Su influencia en las universidades latinoamericanas es notable, constituyendo la base de todos los movimientos reformistas posteriores. 


\section{EL POSREFORMISMO ENTRE GOLPES}

El golpe militar de 1930, que derroca el segundo mandato de Yrigoyen, intervino las universidades reprimiendo a los referentes reformistas y constituyó una bisagra en la vida universitaria con consecuencias directas en sus objetivos explícitos. Se inauguraba un periodo de la historia argentina signado por oscilaciones pendulares entre gobiernos democráticos y de facto que impactaron, con avances y retrocesos, en muy diversas maneras de delinear las políticas en relación con las funciones constitutivas de las universidades y, en consecuencia, en diversos modos de instituirlas, corporizarlas e incluso resistirlas. Si bien gran parte de las conquistas de la Reforma fueron vulneradas durante la llamada década infame, según sostiene Suasnábar (2009), en los años subsiguientes se respetaron aquellas relacionadas con los mecanismos de contratación de los profesores.

Tras una década de gobiernos de corte democrático reunidos bajo "la Concordancia" -alianza labrada entre el Partido Demócrata Nacional, el Partido Socialista Independiente y la Unión Cívica Radical Antipersonalista-, pero signados por sospechas de fraude con posterioridad al gobierno del general Uriburu, un nuevo golpe termina desplazando de sus cargos, en 1943, a muchos profesores que encarnaron una posición ideológica opositora (Hurtado de Mendoza y Busala, 2006) por haber firmado un petitorio en demanda de la restauración democrática, lo que a su vez generó una marcada resistencia en la comunidad académica, caracterizada por la discontinuidad en las clases y las protestas estudiantiles. Esto a su vez impulsó nuevas oleadas de cesantías en un contexto de fuertes represiones y de intervención de las universidades.

\section{LA UNIVERSIDAD EN ÉPOCA DE PERÓN...}

El nuevo periodo de facto que se impone tras la década infame y que se prolonga hasta 1946, culmina con el acceso al gobierno tras elecciones democráticas del general Juan Domingo Perón, quien ocupara con anterioridad la Secretaría de Trabajo, el Ministerio de Guerra y finalmente la vicepresidencia de la nación, cargo del que es destituido durante su detención en la isla Martín García por la desconfianza que sus nexos con el sindicalismo y la popularidad que cosechaba en la población trabajadora (protagonista del 17 de octubre que 
restituye su libertad y debilita definitivamente al gobierno) despertara en el mando del ejército.

El gobierno peronista promovió un proceso de normalización de las universidades nacionales que fue sumamente complejo por la influencia de un sector del ejército en el establecimiento de prioridades académicas, lo que representó para una parte de la comunidad universitaria y en especial para el estudiantado, que encarnaba la tradición reformista y se constituyó en sinónimo de antiperonismo (Pis Diez, 2012), una flagrante vulneración de la autonomía (Suasnábar, 2009).

Durante el gobierno de Perón, a partir de 1946 y, conjuntamente con la regularización de las universidades públicas, se promovió la creación de varios institutos de investigación y se contrataron profesores extranjeros de prestigio que, lejos de incentivar el desarrollo de temas prioritarios para los países centrales de Europa y de Norteamérica, lideraron un proceso de formación de equipos de trabajo que fueran capaces de desarrollar líneas de investigación estratégicas (Hurtado de Mendoza y Busala, 2006) en áreas de importancia como la física, química, hidrología, ingeniería, fitotecnia, genética vegetal, etc., con alto impacto en el desarrollo de la política científica nacional en consonancia con el proceso de desarrollo e industrialización previsto en el marco del Primer Plan Quinquenal.

Este escenario desató un fuerte debate en torno a la reformulación de las funciones vertebrales de las universidades públicas acerca de la pertinencia de la currícula y de su relevancia en la formación de los futuros egresados, así como respecto del diseño de las políticas estatales de desarrollo científico y tecnológico, que supuso un énfasis en la investigación por sobre otras funciones y que tuvo una impronta significativa en el auge de las ciencias aplicadas y especialmente en su transferencia tecnológica, lo que, si bien resulta consecuente con la misión social de estas instituciones, se interpretó como una intromisión respecto de la elección de los temas de investigación.

En este contexto se consolidaron grupos de profesores que, al margen de las líneas prioritarias de investigación propuestas por el Estado, comienzan a desarrollar -nucleados por el doctor Bernardo Houssay, notable médico fisiólogo y acreedor del nobel en ciencias- un modelo de ciencia independiente que es financiado con el aporte de laboratorios y de universidades extranjeras e incluso de la Fundación Rockefeller (Hurtado de Mendoza y Busala, 2006). El liderazgo de Houssey en este enfrentamiento con el modelo de ciencia impulsado por el peronismo alimentó una polémica respecto del 
rol de la ciencia y la política, que si bien excede el propósito de estas reflexiones, pueden rastrearse en algunas contribuciones entre las que se destaca la semblanza de época escrita por Cereijido (2014) y complementada desde otro punto de vista por Varsavsky (1969) en su crítica al cientificismo y a aquello que llama la restauración anacrónica.

Bajo estas tensiones subyace una grieta en el seno de la academia que abarcó a todos sus estamentos y que se explicita en el antagonismo (aún vigente) entre dos concepciones de universidad en torno a la relevancia del conocimiento: la de una ciencia integrada a la planificación estratégica del país como parte de un proyecto de desarrollo nacional (Matus, en Huertas, 2006) y la de un modelo de ciencia liberal que ha consolidado a una aristocracia meritocrática que, enarbolando la bandera de la autonomía, se siente al margen del interés del Estado y de las prioridades de la sociedad, pero cuyos resultados han impactado de manera notoria en la historia de la ciencia nacional. Esta afirmación no pretende desmerecer el valor del trabajo de investigadores de la talla de Houssay, de Luis Leloir y de otros tantos, pero sí visibilizar el trasfondo político que subyace en las decisiones tomadas por muchas academias en relación con la consideración acerca de cuáles temas deben premiarse como relevantes, y que lejos de promover un debate crítico respecto del rol social del conocimiento han contribuido a fomentar un sentido común en relación con la excelencia como categoría, que premia a un modelo de ciencia respecto de otro modelo antagónico al que incluso se ha calificado como mediocre por los mismos sectores hegemónicos desde donde se ejerce el poder.

No obstante, y en contraposición al imaginario de mediocridad académica que se ha pretendido instalar, durante la segunda presidencia de Perón -a partir de la década de los años cincuenta- se inaugura el Instituto Nacional de Investigaciones de las Ciencias Naturales, del Museo Argentino de Ciencias Naturales "Bernardino Rivadavia"; se crea la base experimental de la Antártida como una manera de fomentar la investigación, de proteger los recursos naturales de la región y de garantizar la soberanía en esa porción del continente antártico, conjuntamente con las islas del Atlántico Sur; se firma el decreto que dio origen a la Comisión Nacional de Energía Atómica (CNEA), y se crea el Consejo Nacional de Investigaciones Científicas y Técnicas con el propósito de nuclear de manera descentralizada, tanto en institutos como en universidades, a científicos y diversas líneas de investigación que se desarrollaban en el país. La iniciativa constituyó uno de los ejes centrales de la políti- 
ca estatal para el sector que derivó en el Consejo Nacional de Investigaciones Científicas y Técnicas (CONICET) tal como actualmente se le conoce.

La creación del CONICET, no obstante, también constituyó un espacio de disputa tanto real como simbólica que hoy persiste en el imaginario académico. El anteproyecto fue presentado por la Academia Nacional de Ciencias Exactas, Físicas y Naturales e inspirado en las ideas de la Asociación Argentina para el Progreso de las Ciencias (Galati, 2016) y los aportes del doctor Houssey, quien se convirtiera en su primer presidente (Charreau, 2008) luego que el decreto de Ley 1291/58 promulgado durante la dictadura de Aramburu en 1958, derogara al decreto 9695/51 que, firmado el 17 de mayo de 1951, diera origen al Consejo Nacional de Investigaciones Científicas y Técnicas (CONICYT). Resulta llamativa la manera en que se ha intentado despolitizar la historia de una institución que, aun manteniendo un mismo nombre y propósito, fue renombrada siete años después bajo una nueva sigla. Ello en respuesta a las presiones de un grupo de académicos que encarnaron la disputa histórica en torno al sentido de la ciencia bajo la antinomia liberalismo vs injerencismo estatal, incluso cuando bajo esta concepción liberal, limitar el papel del Estado no limita el financiamiento sino únicamente el establecimiento de las prioridades respecto de la integración de las políticas científicas para la planificación de un proyecto de país que, en ese entonces, encarnaba el Segundo Plan Quinquenal.

A pesar de estas disputas de sentido, la excelencia en la producción científica ha sido un rasgo inmanente del sistema universitario argentino. Aun así, las universidades, lejos de constituirse en el refugio de una elite ilustrada, promovieron el acceso de la población a la educación superior -concebida como un derecho social-, a tal punto que la matrícula se incrementó de 50000 alumnos en 1945, a alrededor de 140000 en 1955 (Ortiz, 2014). En 1949, después de que el decreto 29.337 proclamara el acceso gratuito e irrestricto a la enseñanza universitaria, se produjo una avalancha de ingresantes, en particular de jóvenes de las clases trabajadoras y de los sectores populares. También la fundación en 1948 de la Universidad Obrera -actualmente Universidad Tecnológica Nacional (UTN) - da cuenta de esta concepción de la enseñanza superior que fue interpretada en ese entonces como una afrenta directa a la academia y al empresariado (Sánchez Román, 2008).

Este escenario en el plano educativo no sólo contribuyó a fomentar una política de movilidad social ascendente bajo la bandera de la justicia social, sino que además perteneció a una estrategia orientada a la formación de profesionales capaces de hacer frente al proyecto de desarrollo nacional. En este 
nuevo contexto la ciencia es entendida como un capital cultural (Bourdieu, 1987) y como un bien en disputa que fomentó la politización y polarización de la actividad científica y de la vida académica, generando un quiebre definitivo en el modo de pensar la investigación y la docencia y que abrevó en una falsa dicotomía entre excelencia y relevancia. También se convirtió en un punto de inflexión para la extensión que, apostando a un modelo difusionista (Tommasino y Cano, 2016), se concentra en la divulgación como una manera de garantizar el acceso de la sociedad al conocimiento que es producido en la academia bajo la premisa de que la masificación de estos saberes impacta sinérgicamente en el desarrollo cultural.

\section{GOLPE A GOLPE...}

El gobierno peronista culmina abruptamente con el golpe de Estado del 55 (véase cuadro 1) conocido con el nombre de "Revolución Libertadora", que encabezada en primera instancia el general Eduardo Lonardi y, posteriormente, el general Pedro Aramburu, instala una dictadura militar que es sucedida por los gobiernos radicales - constitucionales- de Arturo Frondizi, José María Guido y Arturo Illia, entre los años 1958 y 1966, este último derrocado por la llamada "Revolución Argentina" bajo la conducción del general Onganía, quien repite la dinámica pendular que reiteradamente truncó los diversos proyectos de restauración democrática en el país. Se inicia así, en 1966, una reforma del Estado bajo un gobierno de facto, cuyo principal objetivo fue disminuir el gasto público en medio de una crisis económica fenomenal y que alcanzó a todos los niveles educativos incluyendo el universitario e inaugurando, en 1955, un periodo signado por la creación de numerosas universidades privadas (véase cuadro 1) que también atravesó a los gobiernos radicales de Frondizi, Guido e Illia, y que tal como pretendía el gobierno de facto de Aramburu, constituyó una forma de delegar la educación superior y de disminuir el gasto público a través del arancelamiento, consolidando un modelo que concentra el conocimiento en aquellas fracciones de la sociedad que pudieran comprarlo.

La noche del 29 de julio de 1966, a tan sólo un mes del derrocamiento del gobierno de Illia, los militares irrumpen violentamente en la Universidad de Buenos Aires, en lo que se conoce como la noche de los bastones largos. Se intervinieron formalmente las universidades, pisoteando la autonomía a tra- 
vés del decreto de Ley 16.912, que limitaba la injerencia de decanos y rectores a meras acciones administrativas, se prohibieron los centros de estudiantes e incluso se interrumpieron las clases durante periodos prolongados en aquellas instituciones que se resistieron al decreto. Un año más tarde se sancionó la llamada ley orgánica de las universidades (Ley 17.245) que fijaba como fin institucional la "formación de universitarios capaces de actuar con responsabilidad y patriotismo al servicio de la nación”, sesgando el verdadero espíritu de estas instituciones (De Luca y Álvarez Prieto, 2013). No obstante, la ley -como otras posteriores- no fue resultado de la improvisación, sino de un diagnóstico exhaustivo de organismos locales e internacionales. Bajo el modelo de una utilización eficiente de los recursos económicos sobre estadísticas respecto de los índices de egresados, se pretendía reducir la matrícula expulsando a aquellos estudiantes con bajos índices de rendimiento, retrocediendo en derechos adquiridos y contribuyendo a la despolitización de las universidades, a pesar de que -paradójicamente-durante este periodo se crean siete universidades nacionales (véase cuadro 1 ).

Una vez restablecido el orden constitucional y luego de las elecciones promovidas por el doctor Héctor Cámpora (quien asumiera brevemente la presidencia de la nación en lo que se conoció como la primavera camporista) se inicia, en 1973, un nuevo gobierno peronista que promueve la sanción de la llamada Ley Taiana (Ley 20.654), elevada al Congreso de la Nación por el entonces Ministro de Educación Jorge Alberto Taiana. La ley propone un nuevo ordenamiento de la vida universitaria y de las funciones que la rigen, entre las que figuran:

promover, organizar y desarrollar la investigación y la enseñanza científica y técnica, pura y aplicada, asumiendo los problemas reales nacionales y regionales, procurando superar la distinción entre trabajo manual e intelectual. La orientación será nacional y tendente a establecer la independencia tecnológica y económica y elaborar, desarrollar y difundir el conocimiento y toda forma de cultura en particular la de carácter autóctono, nacional y popular.

La nueva ley -que sustituyó a la 17.245- pretendía restablecer y ampliar las conquistas posreformistas alcanzadas durante los breves periodos democráticos que fueron interrumpidas y mutiladas por los gobiernos militares y fue acompañada de una gestión del ministro Taiana que, en opinión de Pérez 
Lindo (1985), estuvo orientada a vincular la universidad con las necesidades de la sociedad a través de convenios con empresas y organismos del Estado.

En ese periodo se creó un centro de producción de medicamentos en la UBA en articulación con el Ministerio de Salud de la nación, se intentó reincorporar a aquellos profesores que fueron anteriormente cesanteados y se avanzó en la vinculación curricular con otros ciclos de enseñanza en universidades como la de Luján, Lomas de Zamora y Río Cuarto. Durante su gestión también se crearon institutos destinados a estudiar los problemas de América Latina y del Tercer Mundo e incluso se promovió la creación de equipos de trabajo que pudieran involucrarse en proyectos de interés para las clases populares entre los que se destacó la propuesta de reorganización de las villas de emergencias y la participaron de las universidades en la campaña nacional de reactivación educativa de adultos para la reconstrucción (CREAR) como parte del proyecto nacional de descolonización cultural y socialización de la educación (De la Fare y Villela Pereira, 2011). Además, se fomentó la regularización de las instituciones a través de la elección de autoridades y la conformación de las Asambleas Universitarias.

Rodríguez (2015) señala que este periodo estuvo caracterizado por la conflictividad resultante de la toma de numerosas facultades y de las movilizaciones estudiantiles, tanto en rechazo como en apoyo a la designación de autoridades, lo que contribuyó a una polarización de las opiniones en consonancia con las expectativas de transformación de las universidades públicas.

Asimismo, se suspendieron temporalmente los trámites requeridos para la creación de nuevas universidades, probablemente -agrego- supeditados a la definición de un perfil acorde al proceso de transformación político que comenzaba a acontecer en el país pero que, tal como apunta Rodríguez (2015), comienza a permearse a partir de 1973 con excepciones que autorizan la creación de las universidades de Entre Ríos, Jujuy y Santiago del Estero (véase cuadro 1), entre otras.

En 1976 un nuevo golpe militar autodenominado "Proceso de Reorganización Nacional", que se prolonga hasta 1983, irrumpe como la más feroz dictadura del continente, decapitando la universidad pública, controlando la vida académica e incluso prohibiendo la circulación de libros (Godoy, 2017) $y$, por lo tanto, de ideas y contenidos, restringiendo el ingreso de estudiantes por mecanismos burocráticos como la instalación de cupos, la obligatoriedad de los exámenes eliminatorios y el arancelamiento de trámites (Rodríguez y Soprano, 2009) e incluso se cerraron carreras y se expulsó a profesores por su 
orientación ideológica, persiguiéndolos junto a miles de estudiantes que hoy se cuentan entre las víctimas detenidas-desaparecidas del genocidio de Estado.

Durante este periodo muchos de los rectores "interventores" en representación del gobierno militar e incluso aquellos civiles nombrados posteriormente y provenientes de la derecha más radicalizada, impusieron nuevas restricciones a la autonomía (Rodríguez, 2014), impulsando líneas de investigación "autorizadas" que fueron consistentes con los intereses de la derecha conservadora y con la agenda científica estadunidense concentrada en las ciencias básicas, lo que relegó, desalentó y desfinanció a las ciencias aplicadas en un interés por consolidar un modelo económico agroexportador $y$, sobre todo, prohibiendo la mayoría de temas provenientes de campos como la sociología, la filosofía y la antropología social, entre otras disciplinas.

La docencia, además, se caracterizó por un formato transferencista cuyo propósito era la transmisión y reproducción de contenidos que abrevan en un modelo de "neutralidad" incapaz de promover -incluso- la discusión sobre aspectos disciplinares, con tal verticalidad en las ideas, que se impedía expresamente cualquier manifestación que pudiesen vincular los temas académicos con la política. En este escenario, el conductismo (Skinner, 1979) se constituyó en el fundamento pedagógico de la práctica docente, atravesado por una fuerte impronta homogeneizadora, desarraigada e indiferente respecto del contexto social y de sus problemáticas: una situación que posiciona a las universidades de principios de los años ochenta como una institución de intramuros, acrítica y en la que no existe lugar legitimado para la extensión en ninguna de sus expresiones. A pesar de esto, muchos estudiantes y docentes desarrollaron en esta época una activa militancia barrial de resistencia compatible con el rol social del conocimiento académico que Fernández Varela, Piga y Tünnermann (1981) describen como la misión teleológica de las universidades respecto de la extensión, al vincularlas de forma indirecta con el proceso de transformación social que venía gestándose en la región y que ha sido parte de la génesis de la identidad latinoamericanista.

\section{[BUENOS] AIRES DE DEMOCRACIA...}

La vuelta a la democracia y el inicio de la presidencia de Raúl Alfonsín, en 1983, se caracterizó por la existencia de un clima social atravesado tanto por las tensiones resultantes de las contradicciones y las condicionantes 
heredados de la dictadura militar, como por las expectativas generadas por el restablecimiento del orden constitucional. No es casual que las políticas implementadas por el gobierno alfonsinista se debatieran entonces entre la necesidad de dar respuesta a la multiplicidad de demandas acumuladas en el sector y las limitaciones para introducir cambios en la universidad, como respuesta a la necesidad de no alimentar la imagen de desconfianza que persistía en la academia tras los años de intervención signados por la represión política, el oscurantismo ideológico, las restricciones financieras y la situación de vaciamiento científico y académico (Suasnábar, 2011).

Comienza entonces un proceso de restauración de las funciones universitarias (Martinetto, 2008), reabriendo aquellas carreras que habían sido suprimidas, eliminando las restricciones al ingreso, ampliando los derechos estudiantiles, restituyendo la legitimidad de los claustros, fomentando la discusión política y la reforma de algunos planes de estudio, reincorporando a los profesores cesanteados, sustanciando nuevos concursos docentes y restableciendo la autonomía tanto en lo que respecta a la libertad de cátedra, como a la elección de los temas de investigación. También se comenzó a impulsar la extensión y la recuperación paulatina del rol de la política en la gestión.

Lejos de haber sido un periodo signado por innovaciones de tipo legislativas, constituyó una etapa transicional que permitió restaurar las condiciones preexistentes, incrementándose -según Langer (2010) - tanto el número de establecimientos de educación superior no universitaria como la matrícula universitaria -aunque de manera segmentada- en algunas carreras como psicología, ciencias económicas, medicina y abogacía respecto de años anteriores.

A su vez, la crisis heredada y agravada por el contexto socioeconómico que atravesaba el país limitó considerablemente la contribución financiera del Estado a las universidades públicas y, en consecuencia, el aporte de estas al diseño de un proyecto de desarrollo científico y tecnológico nacional. En este contexto muchos de los profesores reincorporados impulsaron propuestas y debates conducentes a lograr una suerte de modernización y reformas de la institución sobre la base de patrones internacionales en el marco del desembolso de fondos provenientes de organismos externos asociados al Programa de Reforma de la Educación Superior (Suasnábar, 2005), lo que significó una avanzada en relación con la cesión de autonomía respecto de los estándares que vertebran el concepto de universidad global y que tal como sugiere Tünnermann (2006) no sólo se acota a la economía sino también a las finanzas, la cultura, la ciencia, la comunicación y la educación. 


\section{LA UNIVERSIDAD GLOBAL}

El escenario de globalización que se instaló poco tiempo después durante la presidencia de Carlos Menem, impulsó nuevos debates en el seno de las universidades que, en el marco del llamado consenso de Washington y del desembarco del neoliberalismo que comienza a consolidarse en toda la región en la década de los años noventa, condujo a la sanción de la polémica Ley de Educación Superior (LES) (Ley 24.521), una herramienta central en la reconfiguración de las particularidades y tensiones que hoy definen al sistema universitario argentino. Durante estos años, tal como se observa en el cuadro 1 , se incrementa el número de las universidades privadas en el país (Balbo, 2003), con la necesaria adecuación de su oferta de formación académica a las demandas del mercado y con la consecuente articulación entre estas y las públicas, en una suerte de homeostasis que contribuyó a redefinir el modo en que se fueron objetivando la diversidad de funciones que las definen, demarcando modos de habitar la universidad como institución y maneras de contribuir a la construcción y al sostenimiento de sus tradiciones.

En este marco, se pretendió que las universidades se adecuaran a un modelo eficientista que fue respaldado por la figura de un "Estado evaluador" donde la acreditación de carreras como práctica de legitimación de la oferta académica y de certificación de la calidad educativa, constituyó -y aún constituye- un instrumento de ajuste de las funciones universitarias a las políticas estatales. En este sentido, la masividad del ingreso, la calidad de la educación (estimada con base en la relación existente entre los recursos económicos respecto del número de alumnos y docentes) y la eficiencia en el egreso, constituyen algunos de los indicadores que reverberan un debate en el que la revisión y la definición de planes de estudios operan como elemento distractor de una tendencia hacia la estandarización de los objetivos institucionales, que según Vargas Porras (2002) impactan en una homogeneización de la currícula de carreras y planes de estudio entre las diferentes instituciones $y$, por lo tanto -agrego-, del perfil de los futuros egresados en relación con las demandas del mercado, instalándose un tipo de conocimiento hegemónico que no sólo responde a ciertos grupos de poder capaces de consolidar una única visión del mundo, sino que contribuye a desvalorizar las singularidades con un fuerte impacto en la renuncia a la crítica como hábitus y a la naturalización de ciertas posturas en el sentido común de los futuros profesionales $y$, por lo tanto, de la sociedad. 
La LEs ha contribuido a lo largo de estos años a fomentar en la comunidad académica el imaginario acerca de la violación de la autonomía (Tiscornia, 2009), ubicando en el centro de la resistencia y de las transformaciones institucionales a los claustros en ejercicio del cogobierno, a pesar de que este proceso de acreditación y autoevaluación enmascara una profundización del control del Estado sobre la academia. Según Araujo (2014), se habilitó la creación de un mercado de servicios de evaluación bajo la figura de agencias privadas con funciones similares a las de la Comisión Nacional de Evaluación y Acreditación Universitaria (CONEAU) que, finalmente, se constituyó en Argentina como el único organismo con injerencia en la acreditación y que no sólo es un ente descentralizado con participación democrática en su constitución, sino que delega este ejercicio en los propios académicos que de esta manera se convierten en evaluadores de sus propios pares, un ejercicio que se ha ido naturalizando como parte de las tradiciones de un sistema que es meritocrático por excelencia (Vessuri et al, 2014).

Paradójicamente, y a pesar del resistido rechazo de una parte de la comunidad universitaria a las políticas de evaluación, muchos de estos procesos promovieron cambios positivos respecto de algunas prácticas como la investigación, la docencia o la extensión -que explícitamente aparece como función relevante en la letra de la ley-, al fomentar programas de incentivos a la investigación e instancias de capacitación y formación docente.

La LEs también avaló y fomentó otras prácticas que en poco tiempo se incorporaron a la rutina de la vida académica como la transferencia de conocimientos al sector productivo (Juarros, 2005) y los servicios a terceros, la autogestión financiera a través de contratos con empresas privadas (Juarros y Naidorf, 2007) y la modificación periódica de los planes de estudio, aunque una de las visiones más críticas al respecto, sostiene que la reformulación de planes de estudio ha estado orientada a fomentar un paulatino vaciamiento de contenidos en la formación de grado en beneficio de un posgrado arancelado con énfasis en la adecuación del perfil profesional a las demandas coyunturales del mercado laboral y regulando, de manera indirecta, el mercado de ofertas formativas existente entre las universidades estatales y las privadas.

Suasnábar (2005) asegura que estas reformas impuestas durante el menemismo responden a una agenda regida por el Banco Mundial -y en última instancia por las políticas regionales del Fondo Monetario Internacional (FMI) - que han constituido una pieza central de un proceso de deslegitimación de la universidad pública orientado a construir un sentido común en 
torno a la intención de permitir y de avalar el arancelamiento de las universidades bajo la figura de la equidad (que es incluida en la letra de la LES) y no de la gratuidad, en consonancia con el clima de época neoliberal que pone énfasis en los proyectos individuales, en detrimento de los colectivos.

En este contexto se promovió el fortalecimiento del vínculo con empresas privadas, a través de la transferencia de conocimientos en tecnología y servicios, entendida como una suerte de extensión del conocimiento, aunque esto no representó otra cosa que la mercantilización de ese conocimiento bajo la falacia de que el bienestar social está directamente asociado al de las empresas (Langer, 2010), y por lo tanto al desarrollo de sectores concentrados que terminarían "derramando" ese estado de bienestar en la población.

La naturalización de esta posición respecto de la misión social de la universidad, además, fomentó un total desconocimiento del propósito setentista de la extensión universitaria basado en una lógica teleológica (Serna Alcántara, 2007) enfrascada en incidir directamente en el mejoramiento de las condiciones de vida de la sociedad en consonancia con las luchas de los movimientos sociales.

El posicionamiento mercantilista en relación con la universidad, entendida esta como "empresa de servicio", terminó por desvincular simbólicamente a muchas instituciones de su función social transformador, reduciendo la extensión a tareas de asesoramiento bajo la figura de la responsabilidad social (Vallaeys, 2008) e imponiendo en la práctica una suerte de cesión de autonomía debido a que las decisiones respecto de muchas actividades académicas terminan siendo condicionadas por decisiones del directorio de aquellas empresas que las financiaban (Kicillof, 2006) y no por sus consejos académicos o directivos.

\section{EMBATES DE LA OTRA CRISIS}

El fin del menemismo desembocó en un deterioro económico y social que se agudizó notablemente durante el gobierno de la Alianza bajo la presidencia de Fernando de la Rúa, como resultado de la profundización de las políticas neoliberales; el saldo: una crisis sin precedentes con la detonación de la economía, el embargo por parte de los bancos del dinero de sus ahorristas, una inusitada sucesión de presidentes que asumen y se remplazan de manera consecutiva en una misma semana, el aumento desproporcionado de indi- 
cadores como el "riesgo país" ante la declaración del default realizada por el presidente Rodríguez Saá-quien renuncia pocas horas después-respecto del pago de una deuda inconmensurable, resultante del sostenimiento artificial de la paridad monetaria heredada del menemismo y, finalmente, de una crisis institucional imparable que condenó a la pobreza al $57.5 \%$ de la población y a la indigencia a un 27.5 por ciento. ${ }^{2}$

Esta coyuntura afectó severamente a las universidades públicas debido al enorme recorte presupuestario realizado por parte del Estado, lo que promovió la resistencia de gran parte de la comunidad académica y un profundo debate respecto de la relevancia de las universidades en la sociedad con un aumento de la conflictividad social.

La situación sumió a las universidades nacionales en un impasse que postergó definitivamente algunos intentos sutiles de reforma, con base en propuestas tales como el acortamiento de las carreras, el desdoblamiento del grado en un ciclo básico y uno especializado sustentado en un sistema de créditos y la imposición de un modelo que favoreciera la movilidad estudiantil entre diferentes instituciones (Suasnábar, 2005).

Esta realidad impactó sustancialmente en algunas de sus funciones centrales, siendo una de las más afectadas la investigación científica, resquebrajada por la falta de presupuesto y la docencia de grado y posgrado, debido a que se sacrificaron gran parte de los contenidos prescritos en los programas y planes de estudio en favor de clases públicas centradas en el debate de la situación coyuntural en defensa de la educación pública y gratuita, un hecho que en cierta medida contribuyó a recuperar algunas de las tradiciones de las universidades respecto de su función social y política.

En este contexto, la extensión ocupó un papel central, convirtiéndose en una herramienta de trabajo solidario, de acompañamiento a los sectores más castigados por la crisis y en una forma de vincularse objetivamente -desde la academia- con las necesidades de la comunidad local en la que se insertan, aportando estrategias innovadoras de abordaje en torno a algunos de los problemas concretos existentes en el territorio. Esto contribuyó a fortalecer un modelo de extensión que comienza a despegarse del modelo difusionis-

2 INDEC (2002). Incidencia de la Pobreza y de la Indigencia en los aglomerados urbanos. Informe de prensa. Los datos son medidos a través de la Encuesta Permanente de Hogares (EPH), realizada en octubre de 2002 en 31 aglomerados urbanos del país, que cubre el total de los aglomerados con más de 100000 habitantes en todas las capitales de provincias. 
ta y que contribuyó a replantear un debate hacia el interior de las unidades académicas, que derivó en una profunda discusión en torno a los modos de objetivar sus prácticas. Con ello se definieron propósitos y expectativas muy diversas tanto por parte de las universidades como de la comunidad que -por primera vez-comienza a ser tomada en cuenta respecto de la definición de las estrategias institucionales.

\section{UN NUEVO CONTRATO...}

Tras un breve periodo de transición acontecido entre los años 2002-2003 bajo la presidencia del doctor Eduardo Duhalde, y durante el cual las universidades lograron sostenerse en medio del proceso devaluatorio de la moneda, la falta de financiamiento y la administración de la crisis social, llega a la presidencia de la nación lo que autores como García (2016) han dado en llamar una disrupción histórica, encarnada por un proceso nacionalista y popular que irrumpe en medio de la crisis socioeconómica con la figura casi desconocida del entonces gobernador de la provincia de Santa Cruz, el doctor Néstor Kirchner.

Durante el kirchnerismo, periodo que incluye tanto la presidencia del doctor Néstor Kirchner (2003-2007) como los dos mandatos consecutivos (2007-2015) de la doctora Cristina Fernández de Kirchner, el sistema universitario comenzó a fortalecerse paulatinamente en consonancia con la recuperación económica del país tras la renegociación y cancelación de gran parte de la deuda externa. En este periodo se incrementó notablemente la matrícula en respuesta a la creación de ocho universidades privadas y 17 universidades públicas nacionales (véase cuadro 1) situadas en el interior del país y en el conurbano bonaerense.

Al respecto, Marquina y Chiroleu (2015) discuten el mapa universitario en relación con la ubicación de las nuevas instituciones y aseguran, al referirse a la concentración existente en el conurbano bonaerense, que son pocas las que adscriben a una estrategia de localización geográfica, sugiriendo que responden a las demandas de los caudillos políticos o referentes territoriales, aunque no es menor el dato -como insumo para el análisis- que es precisamente el conurbano una de las localidades de la geografía nacional con mayor densidad poblacional, por lo cual la cercanía a este tipo de instituciones ha posibilitado el acceso de jóvenes provenientes de las clases trabajadoras a la educación superior y a la acumulación de capital simbólico, siendo que mu- 
chas veces la oferta formativa contribuye a jerarquizar profesiones de gran demanda y con salida laboral inmediata por su relevancia coyuntural.

También, durante este periodo, muchos jóvenes pudieron acceder a financiamiento del programa PROG.R.ES.AR, o de programas como PODES (destinado a estudiantes con discapacidad o de extracción indígena) o a matricularse en carreras de interés para el desarrollo nacional a través de las becas del Bicentenario (PNBB), lo que representó un mayor acceso a los estudios superiores de quienes constituyen la primera generación de universitarios en su entorno familiar.

Durante este periodo se promovió el giro de fondos a diversas universidades del país, a través de mecanismos de asignación -por concurso- de pequeños presupuestos que si bien representó una gran dispersión de recursos (García de Fanelli, 2008) contribuyó al sostenimiento y al desarrollo de numerosos proyectos y programas de investigación y de extensión en muy diversas unidades académicas y equipos de trabajo. Esta política de acceso a financiamiento descentralizado, definida como una estrategia de "ventanillas múltiples" (Chiroleu, 2018), contribuyó a fomentar en los últimos años la promoción de las diversas funciones que configuran la vida académica y en consecuencia una mayor diferenciación de las instituciones en relación con sus prácticas.

Si bien la mayoría de las unidades académicas se abocaron como función constitutiva a la docencia, desplegando múltiples estrategias para garantizar el ingreso, la equidad en la nivelación de los trayectos formativos y la permanencia en la matrícula (Gorostiaga et al., 2017), debido a los altos índices de abandono en los primeros años como resultado del impacto de la desigualdad social (Arias et al., 2015), muchas de ellas también han desarrollado estrategias eficaces de inserción territorial bajo figuras como el Consejo Social, en respuesta a demandas concretas de la comunidad a través de un contacto directo y sostenido con los gobiernos locales (García de Fanelli, 1997), que lejos de representar una cesión de autonomía constituyó una consustanciación progresiva con las problemáticas locales que fomentó el desarrollo de nuevas líneas de investigación y, fundamentalmente, de proyectos de extensión universitaria in situ como estrategias de intervención territorial y de aprendizaje situado.

A pesar de estas innovaciones, que también incluyeron un incremento del financiamiento destinado a obras con una considerable expansión del patrimonio edilicio de las universidades públicas materializado en reformas 
y nuevos edificios de aulas, laboratorios de investigación y campus universitarios, la crítica más importante al gobierno nacional -desde el sector- estuvo relacionada con un reproche casi generalizado por no impulsar una modificación a la LES, tanto en relación con las exigencias de la evaluación externa y la acreditación de carreras, como por aquellos artículos que entienden a la educación como un servicio y no como un derecho, enarbolando la equitatividad en el acceso a la educación en lugar de su gratuidad.

Algunos de estos aspectos han sido recientemente corregidos por la llamada ley Puiggrós (Ley 25.573) que, promulgada en 2015, representó una manera de saldar "cuentas pendientes". La Ley enfatiza en la concepción de la educación universitaria como un derecho irrestricto y destaca la importancia de su pluralidad, resaltando como una prioridad la formación de profesionales responsables con espíritu crítico, reflexivo, ético y con sensibilidad social. También sostiene la autonomía académica e institucional en lo concerniente a la formulación de los planes de estudio, los proyectos de investigación científica y de extensión, así como los servicios a la comunidad, incluyendo la enseñanza de la ética profesional y la formación y capacitación sobre la problemática de la discapacidad. Uno de los aspectos a destacar respecto de la modificación de la LES es que el proyecto de ley expresa el espíritu de las demandas de la academia y es resultado de los consensos alcanzados a través de las diversas asambleas interclaustros realizadas en la mayoría de las universidades nacionales del país.

\section{CAMBIO DE RUMBO...}

Si bien el triunfo electoral del macrismo como proyecto político de restauración neoliberal ha mantenido algunos compromisos asumidos durante el kirchnerismo con las universidades públicas, los últimos años se han caracterizado por un notable deterioro en el desarrollo de los programas de investigación y de extensión que es resultado, por una parte, del impacto que el programa económico ha generado en la sociedad y, por otra, del poco compromiso que el gobierno ha demostrado con la educación pública. Estos se traslucen de las declaraciones que tanto el presidente de la nación, el ingeniero Mauricio Macri, como la gobernadora de la Provincia de Buenos Aires, licenciada María Eugenia Vidal, han realizado en diferentes intervenciones respecto de las universidades públicas y que vienen acompañadas de una reducción en las 
asignaciones presupuestarias que son parte del ajuste implementado como respuesta a las exigencias devenidas de la toma de créditos por parte del gobierno con el Fondo Monetario Internacional.

Algunos discursos que han intentado perfundir en la sociedad apuntan a reinstalar la discusión respecto del gasto público destinado a las universidades en función de la eficiencia en el egreso, como si las universidades fuesen una "fábrica de producir" profesionales que deben graduarse en el menor tiempo posible para satisfacer un mercado que, paradójicamente no demanda -como resultado de las propias políticas de gobierno- mano de obra calificada.

La polémica intenta redirigir nuevamente la discusión hacia la construcción de un sentido común en torno a una universidad elitista con una matrícula más acotada, que demanda un menor presupuesto y que con base en este, se ve requerida a reajustar temas de investigación, obligando -en consecuencia- a sus investigadores a reconfigurar líneas de trabajo en busca de subsidios provenientes del exterior que los "obliga" a trabajar en temas que muchas veces son ajenos a la realidad nacional y que, indirectamente, terminan por retraer el tímido proceso de descolonización, que pudo haberse iniciado años atrás y que tal como sostiene Castro Gómez (2007), no sólo debería incluir a la episteme o las tradiciones ancladas a la historia de las disciplinas, sino también a la estructura "arbórea" que la conforma y en la que anida su andamiaje administrativo jerárquico.

\section{LÍMITES EN LA PRÁCTICA ACADÉMICA...}

De las líneas anteriores podría extraerse la idea de que la historia de las universidades argentinas ha sido también la historia del modo en que se han ido objetivando las funciones académicas y se han ido consolidando como objetivos constitutivos de sus estatutos como parte de un proceso de diferenciación que ha ido aconteciendo en cada una de las instituciones en el marco del ejercicio de la autonomía, un concepto que representa los más altos ideales académicos y que aglutina a las diferentes fracciones que constituyen cada uno de sus claustros, aun en medio de la polémica acerca de la función social de estas instituciones y de las tensiones que puedan existir entre las diferentes tribus (Becher, 1993) que en ella coexisten, del hábitus propio de las disciplinas 
nativas de los académicos (Bourdieu, 2008) y del contexto en que estas prácticas se explicitan.

Estas tradiciones han contribuido a instituir diversos modos de entender la práctica y de reproducirla; en este sentido, la metodología ha sido uno de los elementos definitorios en la distinción entre docencia, investigación, extensión o transferencia.

El objeto de conocimiento, y en especial la hegemonía de ciertas prácticas procedimentales hacia el interior del campo de la investigación, también han contribuido a instalar ciertos prejuicios respecto de la legitimidad del conocimiento, en relación con su naturaleza e incluso en la delimitación entre las llamadas ciencias formales y fácticas; $y$, dentro de estas, entre las ciencias naturales, exactas y las sociales o entre las básicas y aplicadas, con el prestigio diferencial que -al menos en el país- han logrado acumular unas y con la demonización que otras han experimentado, en particular durante las etapas más oscuras de la historia argentina y sudamericana.

Pareciera entonces que la investigación ha constituido una práctica de excelencia que otorga prestigio a quienes la desarrollan $y$, por supuesto, a aquellas universidades que la financian, aunque claramente esta posibilidad de financiamiento y de distribución diferencial del mismo hacia el interior de las instituciones depende de diferentes factores coyunturales entre los que se imponen las políticas estatales para el sector, en relación con la distribución del presupuesto, es decir, con la gravitación que este tiene especialmente en las universidades públicas.

Uno de los aspectos que ha operado como descriptor y límite entre las prácticas académicas ha sido la producción de conocimientos. La investigación se ha arrogado este atributo, relegando a la extensión y a la docencia a habitar un imaginario donde sólo es posible la transferencia de un conocimiento legitimado académicamente, que es traducido a formatos comprensibles ya sea para un estudiantado en formación o para la generalidad de la sociedad. No obstante, ni la docencia es transferencia pasiva de saberes disciplinares, ni la extensión puede reducirse a la divulgación científica, en tanto que la transferencia como concepto tampoco se restringe a los procesos de transposición de saberes, sino que constituye otra de las funciones de las universidades (Langer, 2010) que, por otra parte, ha adquirido en los últimos años mayor relevancia - probablemente- por su impacto en el desarrollo tecnológico.

Los límites que en algún momento fueron imponiéndose y caracterizando cada una de estas prácticas, hoy comienzan a solaparse, ya sea por 
la diversificación de las funciones mismas en el modo en que se objetivan o porque los docentes, además de impartir clases, investigan en un tema en particular, relacionado con la materia que enseñan y en muchos casos se involucran en proyectos de extensión que se desarrollan en el territorio, en actividades de divulgación o en procesos de transferencia tecnológicas y asesoramiento al sector productivo.

No es objeto del presente trabajo establecer una exhaustiva taxonomía de las prácticas académicas, aunque en el análisis de los casos puntuales existen aspectos que permiten definirlas indubitablemente y otros en los que las fronteras entre investigación y extensión -por citar un ejemplo- no son tan claras ya sea porque los problemas del territorio configuran preguntas a resolver con metodologías diversas o porque los resultados de las investigaciones son trasladados a otros contextos de aplicación o constituyen un punto de partida para el trabajo territorial, la divulgación científica o la actualización de contenidos en el aula.

Esta idea de que algunos límites puedan desdibujarse o que al menos las fronteras entre las funciones -tal como han sido impuestas por las tradiciones- puedan ser permeables y dúctiles, es un proceso emergente de la propia complejidad de la práctica académica y de la perspectiva constructivista que comienza a incorporarse, tanto desde el concepto de conocimiento pluriuniversitario que introduce Sousa Santos (2007), como en la génesis de lo que se ha dado en llamar las prácticas integrales (Kaplún, 2016), siendo que la integración de saberes de diversa naturaleza y de metodologías de trabajo, no sólo abarca un enfoque multidisciplinar en la lectura de la realidad, sino también una legitimación del rol de la (inter)subjetividad en la construcción de un conocimiento que es $y$ ha sido multidimensional por naturaleza, aun cuando fuera fragmentado en los albores del racionalismo como estrategia asociada a la comprensión de los problemas.

\section{A MODO DE CONCLUSIÓN}

Tal como hemos visto, podría afirmarse entonces que la historia de las universidades argentinas y de los modos de habitarla, no puede desvincularse de la historia nacional, ni de los avatares de la economía ni de las decisiones políticas de las diferentes administraciones bajo las cuales subyacen concepciones ideológicas que dan cuenta de un determinado modelo de país. 
La profesión académica y en consecuencia su identidad -o las diversas identidades que la constituyen- no ha sido ajena a esta dinámica, de modo que los límites entre cada una de las funciones explícitas de las universidades -y entre cada una de las instituciones- se han ido configurando dialécticamente como resultado de estos contextos y de los modos en que las tradiciones han logrado instituirse, diferenciarse, perpetuarse y/o transformarse, como parte de un proceso de construcción de sentido que en la actualidad propende a diluirlos en favor de la integralidad de una práctica que no puede escindirse del escenario en el que se encuentra inmersa.

\section{LISTA DE REFERENCIAS}

Araujo, S. (2014). La evaluación y la Universidad en Argentina: políticas, enfoques y prácticas. Revista de la Educación Superior, 43(172), 57-77. DoI: https://doi.org/10.1016/j.resu.2015.03.009

Acevedo Tarazona, Á. (2011). A cien años de la reforma de Córdoba, 1918-2018. La época, los acontecimientos, el legado. Historia y Espacio, 7(36), 1-14. Recuperado de https://historiayespacio.univalle.edu.co/index.php/historia_y_espacio/issue/ view/195

Arias, M. F., Mihal, I., Lastra, K. y Gorostiaga, J. (2015). El problema de la equidad en las universidades del conurbano bonaerense en Argentina: un análisis de políticas institucionales para favorecer la retención. Revista Mexicana de Investigación Educativa, 20(64), 47-69. Recuperado de http://www.comie.org.mx/revista/v2018/ rmie/index.php/nrmie/article/view/117

Balbo, C. (2003). Historia de las universidades argentinas de gestión privada. 45 Aniversario. Consejo de Rectores de Universidades Privadas. Buenos Aires: Ed. Dunken.

Becher, T. (1993). Las disciplinas y la identidad de los académicos. Pensamiento Universitario, 1(1).

Becher, T. (2001). Tribus y territorios académicos: la indagación intelectual y las culturas de las disciplinas. Barcelona, Ed. Gedisa.

Bourdieu, P. (1987). Los tres estados del capital cultural. Sociológica México, 2(5), 1-5. Recuperado de http://www.sociologicamexico.azc.uam.mx/index.php/ Sociologica/article/view/1043

Bourdieu, P. (2008). Homo Academicus. Buenos Aires: Siglo XXI.

Castro-Gómez, S. (2007). Decolonizar la universidad. La hybris del punto cero y el diálogo de saberes. En S. Castro-Gómez y R. Grosfoguel (comps.), El giro deco- 
lonial. Reflexiones para una diversidad epistémica más allá del capitalismo global (pp. 79-91). Bogotá: Siglo del Hombre Editores/Universidad Central/Instituto de Estudios Sociales Contemporáneos/Pontificia Universidad Javeriana/Instituto Pensar. Cereijido, M. (2014). La nuca de Houssay: la ciencia argentina entre Billiken y el exilio. México: Fondo de Cultura Económica.

Charreau, E. (2008). Conmemoración del quincuagésimo aniversario del ConICET. Medicina, 68(3), 261-262. Recuperado de http://www.scielo.org.ar/scielo. php?script=sci_arttext\&pid=S0025-76802008000300013\&lng=es\&tlng=es

Chiroleu, A. (2018). Democratización e inclusión en la Universidad Argentina: sus alcances durante los gobiernos Kirchner (2003-2015). Educação em Revista, 34, 1-26. DOI: http://doi.org/10.1590/0102-4698176003

De la Fare, M. y Villela Pereira, M. (2011). Educación de jóvenes y adultos, políticas educativas nacionales y experiencias de educación popular en Argentina y Brasil en los años 60 e inicios de los 70. Revista Interamericana de Educación de Adultos, 33(1), 6-24. Recuperado de https://www.redalyc.org/articulo.oa?id=4575/457545092002

De Luca, R. y Álvarez Prieto, N. (2013). La sanción de la Ley Orgánica de las Universidades en la Argentina bajo la dictadura de Onganía y la intervención de los distintos organismos nacionales e internacionales en el diseño de las transformaciones. Perfiles Educativos, $\operatorname{xxxV(139),~110-126.~DoI:~https://doi.org/10.22201/~}$ iisue.24486167e.2013.139.35715

Fernández Varela, V. J., Piga, D. y Tünnermann, C. (1981). Notas sobre la conceptualización de la extensión universitaria. México: Universidad Nacional Autónoma de México.

Fresán Orozco, M. (2004). La extensión universitaria y la universidad pública. Reencuentro. Análisis de Problemas Universitarios, 39, 47-54. Recuperado de https:// reencuentro.xoc.uam.mx/index.php/reencuentro/article/view/477

Juarros, M. F. (2005). Transferencia Científica. Un estudio de caso sobre las políticas de vinculación Universidad-Sector Productivo. Cinta de Moebio, 22, 127-136. Recuperado de https://www.moebio.uchile.cl/22/juarros.html

Juarros, F. y Naidorf, J. (2007). Modelos universitarios en pugna: democratización o mercantilización de la universidad y del conocimiento público en Argentina. Avaliação: Revista da Avaliação da Educação Superior, 12(3), 483-504. DoI: https:// doi.org/10.1590/S1414-40772007000300006

Galati, E. (2016). Filosofía de la gestión de la ciencia en Argentina a partir de la historia del Conicet. Cinta de Moebio, 55, 80-95. Recuperado de https://cintademoebio. uchile.cl/index.php/CDM/article/view/38954 
García, N. B. (2016). "Que se vayan todos”. Néstor Kirchner y Jorge Sobisch desde la Patagonia. Territorio y liderazgos en pugna. Anuario de la Facultad de Ciencias Humanas, 13(13), 33-49. Recuperado de https://cerac.unlpam.edu.ar/index.php/ anuario/article/view/1364

García de Fanelli, A. (2008). Contrato-programa: instrumento para la mejora de la capacidad institucional y la calidad de la universidad. Buenos Aires, Argentina: IIPE-UnEsco. Recuperado de http://repositorio.cedes.org/handle/123456789/4121

García de Fanelli, A. M. (1997). Las nuevas universidades del conurbano bonaerense: misión, demanda externa y construcción de un mercado académico. Buenos Aires: CEDEs (Serie Educación Superior, 117). Recuperado de http://repositorio. cedes.org/handle/123456789/3550

Godoy, C. (2017). Memorias públicas e historia: un diálogo en claroscuro. En C. Kaufman (ed.), Dictadura y educación: universidad y grupos académicos argentinos (19761983). (T. 1, cap. 2, pp. 61-94). Salamanca: FahrenHouse.

Gorostiaga, J., Lastra, K. y De Britos, S. M. M. (2017). Políticas institucionales para favorecer el acceso y la permanencia en universidades argentinas: un análisis de cuatro instituciones del conurbano bonaerense. Páginas de Educación, 10(1), 151173. DoI: https://doi.org/10.22235/pe.v10i1.1363

Huertas, F. (2006). Planificar para gobernar: El método PEs. Entrevista a Carlos Matus. San Justo, Buenos Aires: Universidad Nacional de La Matanza.

Hurtado de Mendoza, D. y Busala, A. (2006). De la "movilización industrial" a la "Argentina científica": la organización de la ciencia durante el peronismo (19461955). Revista da Sociedade Brasileira de História da Ciência, 4(1), 17-33. Recuperado de https://www.sbhc.org.br/revistahistoria/view?ID_REVISTA_HISTORIA=15

Kaplún, G. (2016). La integralidad como movimiento instituyente en la universidad. InterCambios. Dilemas y Transiciones de la Educación Superior., 1(1), 44-51. Recuperado de https://ojs.intercambios.cse.udelar.edu.uy/index.php/ic/article/view/11

Kicillof, A. (1 de diciembre, 2006). ¿Negocios o academia? Página/12.

Lander, E. (1998). Eurocentrismo y colonialismo en el pensamiento social latinoamericano. En R. Breceño-León y H. R. Sonntag (comps.), Pueblo, época y desarrollo: la sociología de América Latina (pp. 87-96). Venezuela: Nueva Sociedad/Universidad Central de Venezuela. Recuperado de https://www.tni.org/es/art\%C3\%ADculo/ eurocentrismo-y-colonialismo-en-el-pensamiento-social-latinoamericano

Langer, A. (2010). Investigación, transferencia, extensión y docencia: Análisis de las concepciones en la política científica y universitaria de la Argentina. Recuperado de http://www.anped11.uerj.br/28/Langer\%20Ariel.doc 
Martinetto, A. B. (2008). La década de 1980 en la universidad pública. Normalización post-dictadura y transición hacia la reforma de los años 1990. EccoS-Revista Científica, 10(2), 499-519. Recuperado de https://www.redalyc.org/articulo. oa?id=715/71511645012

Marquina, M. y Chiroleu, A. (2015). ¿Hacia un nuevo mapa universitario? La ampliación de la oferta y la inclusión como temas de agenda de gobierno en Argentina. Propuesta Educativa, 43, 7-16. Recuperado de https://ri.conicet.gov.ar/ handle/11336/53882

Mollis, M. (2009). Universidades nacionales y transnacionales. Siglos XIX al XXI. En P. Gentili (ed.), Políticas de privatización, espacio público y educación en América Latina. (pp. 225-237). Rosario: Clacso/Homosapiens Editores. Recuperado de http:// biblioteca.clacso.edu.ar/clacso/gt/20160229022625/cap9.pdf

Ortiz, T. (2014). La Facultad de Derecho y Ciencias Sociales de la Universidad de Buenos Aires en los tiempos del Primer Peronismo (1946-1955). En Nuevos aportes a la historia de la Facultad de Derecho de la Universidad de Buenos Aires (pp. 9-46). Buenos Aires: Departamento de Publicaciones-Facultad de Derecho-Universidad de Buenos Aires.

Pérez Lindo, A. (1985). Universidad, política y sociedad. Buenos Aires: Eudeba.

Pis Diez, N. (2012). La política universitaria peronista y el movimiento estudiantil reformista: actores, conflictos y visiones opuestas (1943-1955). Los Trabajos y los Días, 3, 41-63. Recuperado de https://revistas.unlp.edu.ar/LosTrabajosYLosDias/ article/view/5749

Rodríguez, L. G. y Soprano, G. (2009). La política universitaria de la dictadura militar en la Argentina: proyectos de restauración del sistema de educación superior (1976-1983). Nuevo Mundo Mundos Nuevos. DoI: https://doi.org/10.4000/ nuevomundo.56023

Rodríguez, L. G. (2014). La Universidad Argentina durante la última dictadura: actitudes y trayectorias de los rectores civiles (1976-1983). Revista Binacional Brasil-Argentina, 3(1), 135-160. Recuperado de https://ri.conicet.gov.ar/handle/11336/35227

Rodríguez, L. G. (2015). La universidad durante el tercer gobierno peronista (19731976). Conflicto Social, 7(12), 114-145. Recuperado de https://publicaciones.sociales. uba.ar/index.php/CS/article/view/580

Sánchez Román, J. A. (2008). De las escuelas de artes y oficios a la Universidad obrera nacional: Estado, elites y educación técnica en Argentina, 1914-1955. CIAN Revista de Historia de las Universidades, 10, 269-299. Recuperado de https://e-revistas. uc3m.es/index.php/CIAN/article/view/1178 
Serna Alcántara, G. A. (2007). Misión social y modelos de extensión universitaria: del entusiasmo al desdén. Revista Iberoamericana de Educación, 43(3), 1-7. DoI: https://doi.org/10.35362/rie4332324

Skinner, B. (1979). Tecnología de la enseñanza. Barcelona, España: Ed. Labor.

Sousa Santos, B. (2007). La universidad en el siglo XXI. Para una reforma democrática y emancipadora de la universidad. La Paz: Plural Editores (Colección Universidad). Recuperado de http://www.boaventuradesousasantos.pt/media/universidad_siglo_xxi-.pdf

Suasnábar, C. (2005). Entre la inercia y la búsqueda de una nueva agenda de política: las políticas universitarias en el gobierno de Kirchner. Temas y Debates, 10, 83-93. DoI: https://doi.org/10.35305/tyd.v0i10.169

Suasnábar, C. (2009). La Reforma Universitaria de Córdoba de 1918: una mirada histórica de la relación entre intelectuales, universidad y política en la Argentina. Práxis Educativa, 4(1), 51-61. DoI: https://doi.org/10.5212/PraxEduc.v.4i1.051061

Suasnábar, C. (2011). Políticas y reformas de la universidad argentina desde el retorno a la democracia: tendencias históricas de cambio y movimiento pendular de las políticas públicas. Pensamiento Jurídico, 31, 87-103. Recuperado de https://revistas. unal.edu.co/index.php/peju/article/view/36726

Tiscornia, L. M. (2009). El sistema de acreditación de las universidades nacionales a través de la coneAu frente a la autonomía universitaria. Fundamentos en $\mathrm{Hu}$ manidades, X(20), 45-54. Recuperado de https://www.redalyc.org/comocitar. oa?id=18412520004

Tommasino, H. y Cano, A. (2016). Modelos de extensión universitaria en las universidades latinoamericanas en el siglo xxi: tendencias y controversias. Universidades, 67, 7-24. Recuperado de http://www.redalyc.org/articulo.oa?id=37344015003

Tünnermann, C. (1998). La reforma universitaria de Córdoba. Revista Educación Superior y Sociedad, 9(1), 103-127.

Tünnermann, C. (2006). La autonomía universitaria frente al mundo globalizado. Universidades, 31, 17-40. Recuperado de https://www.redalyc.org/articulo. oa?id=373/37303103

Vallaeys, F. (2008). ¿Qué es la responsabilidad social universitaria? Recuperado de http://repositorio.pucp.edu.pe/index//handle/123456789/11974

Vargas Porras, A. (2002). La acreditación: una forma de estandarizar la educación. Revista Educación, 26(2), 245-254. DoI: https://doi.org/10.15517/revedu.v26i2.2923

Varsavsky, O. (1969). Ciencia, política y cientificismo. Buenos Aires: Centro Editor de América Latina. 
Villa Pacheco, B. (2005). Sobre el lugar común: La universidad humboldtiana puede ser correcta en teoría, pero no vale para la práctica. Logos. Anales del Seminario de Metafísica, 38, 273-281. Recuperado de https://revistas.ucm.es/index.php/ASEM/ article/view/ASEM0505110273A

Vessuri, H., Guédon, J. C. y Cetto, A. M. (2014). Excellence or quality? Impact of the current competition regime on science and scientific publishing in Latin America and its implications for development. Current Sociology, 62(5), 647-665. Dor: https://doi.org/10.1177/0011392113512839 


\section{Cuadro 1. Reconstrucción histórica de la fundación de las Universidades Argentinas.}

\begin{tabular}{|c|c|c|c|c|c|c|c|c|}
\hline Gobierno & Presidencia & Año & Presidente & Universidad & Institución & Fecha & Ley/Decreto & Provincia \\
\hline $\mathbb{S}$ & $\mathrm{C}$ & 2015-2019 & Macri, Mauricio & & & & & \\
\hline \multirow[t]{12}{*}{$\mathbb{S}$} & $\mathrm{C}$ & 2011-2015 & $\begin{array}{l}\text { Fdez. de Kirchner, } \\
\text { Cristina }\end{array}$ & UN & $\begin{array}{l}\text { Universidad Nacional de San Antonio } \\
\text { de Areco (UNSADA) }\end{array}$ & 3-Dic-2015 & 27.213 & Areco, Buenos Aires \\
\hline & & & & UN & $\begin{array}{l}\text { Universidad Nacional Raúl Scalabrini } \\
\text { Ortiz (UNSO) }\end{array}$ & 25-Nov-2015 & 27.212 & $\begin{array}{l}\text { San Isidro, Buenos } \\
\text { Aires }\end{array}$ \\
\hline & & & & UN & $\begin{array}{l}\text { Universidad Nacional Almirante } \\
\text { Guillermo Brown (UNAB) }\end{array}$ & 31-Oct-2015 & 27.193 & $\begin{array}{l}\text { Alte. Brown, Buenos } \\
\text { Aires }\end{array}$ \\
\hline & & & & UP & Universidad Salesiana (UNISAL) & 31-Mar-2015 & $439 / 14$ & $\begin{array}{l}\text { Bahía Blanca, Buenos } \\
\text { Aires }\end{array}$ \\
\hline & & & & UN & $\begin{array}{l}\text { Universidad Nacional del Alto Uru- } \\
\text { guay (UNAU) }\end{array}$ & 10-Dic-2014 & 27.074 & San Vicente, Misiones \\
\hline & & & & UN & $\begin{array}{l}\text { Universidad Nacional de Rafaela } \\
\text { (UNRAF) }\end{array}$ & 3-Dic-2014 & 27.062 & Rafaela, Santa Fe \\
\hline & & & & UN & $\begin{array}{l}\text { Universidad Nacional de Hurlingham } \\
\text { (UNAHUR) }\end{array}$ & 2-Dic-2014 & 27.016 & $\begin{array}{l}\text { Hurlingham, Buenos } \\
\text { Aires }\end{array}$ \\
\hline & & & & UN & $\begin{array}{l}\text { Universidad de la Defensa Nacional } \\
\text { (UNDEF) }\end{array}$ & 12-Nov-2014 & 27.015 & $\begin{array}{l}\text { Ciudad Autónoma de } \\
\text { Bs. As. }\end{array}$ \\
\hline & & & & UN & $\begin{array}{l}\text { Universidad Nacional de los Come- } \\
\text { chingones (UNLC) }\end{array}$ & 7-Nov-2014 & 26.998 & Merlo, San Luis \\
\hline & & & & UN & $\begin{array}{l}\text { Universidad Nacional de las Artes } \\
\text { (UNA) }\end{array}$ & 22-Oct-2014 & 26.997 & $\begin{array}{l}\text { Ciudad Autónoma de } \\
\text { Bs. As. }\end{array}$ \\
\hline & & & & UP & $\begin{array}{l}\text { Universidad Católica de las Misiones } \\
\text { (UCAMI) }\end{array}$ & 28-Mar-2014 & $1643 / 12$ & Posadas, Misiones \\
\hline & & & & UP & $\begin{array}{l}\text { Universidad Metropolitana de la Edu- } \\
\text { cación y el Trabajo (UMET) }\end{array}$ & 1-May-2013 & $1641 / 12$ & $\begin{array}{l}\text { Ciudad Autónoma de } \\
\text { Bs. As. }\end{array}$ \\
\hline
\end{tabular}




\begin{tabular}{|c|c|c|c|c|c|c|c|c|}
\hline Gobierno & Presidencia & Año & Presidente & Universidad & Institución & Fecha & Ley/Decreto & Provincia \\
\hline & & & & UP & Universidad de San Isidro (USI) & 11-Sept-2012 & $1642 / 12$ & $\begin{array}{l}\text { San Isidro, Buenos } \\
\text { Aires }\end{array}$ \\
\hline \multirow[t]{10}{*}{$\mathbb{S}$} & \multirow[t]{10}{*}{$\mathrm{C}$} & \multirow[t]{10}{*}{$2007-2011$} & \multirow[t]{10}{*}{$\begin{array}{l}\text { Fdez. de Kirchner, } \\
\text { Cristina }\end{array}$} & UN & $\begin{array}{l}\text { Universidad Nacional de Tierra del } \\
\text { Fuego (UNTDF) }\end{array}$ & 28-Dic-2010 & 26.559 & $\begin{array}{l}\text { Ushuaia, Tierra del } \\
\text { Fuego }\end{array}$ \\
\hline & & & & UN & $\begin{array}{l}\text { Universidad Nacional de José C. Paz } \\
\text { (UnPAZ) }\end{array}$ & 29-Dic-2009 & 26.577 & $\begin{array}{l}\text { José C. Paz, Buenos } \\
\text { Aires }\end{array}$ \\
\hline & & & & UN & $\begin{array}{l}\text { Universidad Nacional Arturo Jauretche } \\
\text { (UNAJ) }\end{array}$ & 29-Dic-2009 & 26.576 & $\begin{array}{c}\text { Florencio Varela, } \\
\text { Buenos Aires }\end{array}$ \\
\hline & & & & UN & $\begin{array}{l}\text { Universidad Nacional de Moreno } \\
\text { (UNMO) }\end{array}$ & 29-Dic-2009 & 26.575 & Moreno, Buenos Aires \\
\hline & & & & UN & $\begin{array}{l}\text { Universidad Nacional de Avellaneda } \\
\text { (UNDAV) }\end{array}$ & 7-Dic-2009 & 26.543 & $\begin{array}{l}\text { Avellaneda, Buenos } \\
\text { Aires }\end{array}$ \\
\hline & & & & UN & Universidad Nacional del Oeste (unO) & 11-Nov-2009 & 26.544 & Merlo, Buenos Aires \\
\hline & & & & UN & $\begin{array}{l}\text { Universidad Nacional de Villa Merce- } \\
\text { des (UNVIME) }\end{array}$ & 11-Nov-2009 & 26.542 & $\begin{array}{l}\text { Villa Mercedes, San } \\
\text { Luis }\end{array}$ \\
\hline & & & & UP & Universidad Gastón Dachary (UGD) & 25-Feb-2009 & $138 / 09$ & Posadas, Misiones \\
\hline & & & & UP & Universidad del Este (UDE) & 29-Sept-2008 & $1557 / 08$ & La Plata, Buenos Aires \\
\hline & & & & UN & $\begin{array}{l}\text { Universidad Nacional de Río Negro } \\
\text { (UNRN) }\end{array}$ & 19-Dic-2007 & 26.330 & Viedma, Río Negro \\
\hline \multirow[t]{3}{*}{$\mathbb{S}$} & \multirow[t]{3}{*}{$\mathrm{C}$} & \multirow[t]{3}{*}{ 2003-2007 } & \multirow[t]{3}{*}{ Kirchner, Néstor } & UP & Universidad isalud (UI) & 7-Dic-2007 & 1914/07 & $\begin{array}{l}\text { Ciudad Autónoma de } \\
\text { Bs. As. }\end{array}$ \\
\hline & & & & UP & $\begin{array}{l}\text { Universidad Nacional del Chaco Aus- } \\
\text { tral (UNCAUS) }\end{array}$ & 4-Dic-2007 & 26.335 & Sáenz Peña, Chaco \\
\hline & & & & UP & Universidad de San Pablo (USPT) & 4-Julio-2007 & $859 / 07$ & San Miguel, Tucumán \\
\hline \multirow[t]{2}{*}{$\mathbb{S}$} & \multirow[t]{2}{*}{$\mathrm{C}$} & \multirow[t]{2}{*}{$2002-2003$} & \multirow[t]{2}{*}{ Duhalde, Eduardo } & UN & $\begin{array}{l}\text { Universidad Nacional del Noroeste de } \\
\text { la Prov. Bs. As. (UNNOBA) }\end{array}$ & 19-Nov-2003 & 25.824 & Junín, Buenos Aires \\
\hline & & & & UN & Universidad Nacional de Chilecito & $5-N o v-2003$ & 25.813 & Chilecito, La Rioja \\
\hline
\end{tabular}


Fecha Ley/Decreto

Provincia

UP

$\begin{array}{ll}\mathbb{S} & \mathrm{C} \\ \mathbb{S} & \mathrm{R} \\ \mathbb{S} & \mathrm{C} \\ \mathbb{S} & \mathrm{R} \\ \mathbb{S} & \mathrm{C} \\ & \\ \mathbb{S} & \mathrm{C}\end{array}$

2001-2002 Caamaño, Eduard

2001-2001 Rodríguez Saá, Adolfo

2001-2001 Puerta, Ramón

1999-2001 De la Rua, Fernando

1995-1999 Menem, Carlos Saúl

1989-1995 Menem, Carlos Saúl

\section{Universidad del Cine (FUC)}

Universidad Adventista del Plata (UAP)
11-Abr-2003 586/03

9-May-2002 795/02
Ciudad Autónoma de Bs. As.

San Martín, Entre

Universidad del Gran Rosario (UGR)

Universidad Favaloro (UF)

22-Jun-2000 549/06

30-Ago-1998 1515/98

15-Ago-1995 2330/93

Universidad Abierta Interamerican (UAI)

$\begin{array}{lll}\text { Universidad Nacional de Lanús (UNLA) } & \text { 7-Jun-1995 } & 24.496 \\ \text { Universidad Nacional de Tres de Febre- } & \text { 7-Jun-1995 } & 24.495\end{array}$

Universidad Nacional de Tres de Febre- 7-Jun-1995 24.495 ro (UNTREF)

Universidad Nacional de Villa María

19-Abr-1995 24.484 (UNVM)

Universidad Empresarial Siglo XXI (ues21)

Universidad de Congreso (UC)

Universidad de Flores (UFLO)

19-Ene-1995 90/95

28-Dic-1994 2377/94

28-Dic-1994 2361/94

Universidad Nacional de la Patagonia Austral (UNPA)

Universidad Atlántida Argentina (UAA) $\quad$ 5-Abr-1994 491/94

Universidad de la Cuenca del Plata (UCP)
Ríos

Rosario, Santa Fe

Ciudad Autónoma de Bs. As.

Ciudad Autónoma de Bs. As.

Lanús, Buenos Aires

3 de Febrero, Buenos

Aires

Villa María, Córdoba

Ciudad de Córdoba,

Córdoba

Mendoza

Ciudad Autónoma de

Bs. As.

Caleta Olivia, Santa Cruz

Mar de Ajó, Buenos Aires

Corrientes, Formosa, Chaco 


\begin{tabular}{|c|c|c|c|c|c|c|c|c|}
\hline \multirow[t]{15}{*}{ Gobierno } & Presidencia & Año & Presidente & Universidad & Institución & Fecha & Ley/Decreto & Provincia \\
\hline & & & & UN & $\begin{array}{l}\text { Universidad Nacional de La Rioja } \\
\text { (UNLAR) }\end{array}$ & 28-Sept-1993 & 24.299 & La Rioja \\
\hline & & & & UP & $\begin{array}{l}\text { Universidad del Centro Educativo } \\
\text { Latinoamericano (UCEL) }\end{array}$ & 3-Dic-1992 & $3502 / 92$ & Rosario, Santa Fe \\
\hline & & & & UP & Universidad del cema (UCEMA) & 26-Oct-1992 & $1655 / 97$ & $\begin{array}{l}\text { Ciudad Autónoma de } \\
\text { Bs. As. }\end{array}$ \\
\hline & & & & UN & $\begin{array}{l}\text { Universidad Nacional de Gral. San } \\
\text { Martín (UNSAM) }\end{array}$ & 10-Jun-1992 & 24.092 & $\begin{array}{l}\text { San Martín, Buenos } \\
\text { Aires }\end{array}$ \\
\hline & & & & UN & $\begin{array}{l}\text { Universidad Nacional de Gral. Sar- } \\
\text { miento (UNGS) }\end{array}$ & 20-May-1992 & 24.082 & $\begin{array}{l}\text { Malvinas, Buenos } \\
\text { Aires }\end{array}$ \\
\hline & & & & UP & Universidad Austral (UA) & 16-Oct-1991 & $300 / 02$ & Buenos Aires \\
\hline & & & & UP & $\begin{array}{l}\text { Universidad de Ciencias Empresariales } \\
\text { y Sociales (UCES) }\end{array}$ & 4-Oct-1991 & $870 / 91$ & Buenos Aires \\
\hline & & & & UP & Universidad Torcuato Di Tella (UTDT) & 24-Sept-1991 & $841 / 91$ & $\begin{array}{l}\text { Ciudad Autónoma de } \\
\text { Bs. As. }\end{array}$ \\
\hline & & & & UP & Universidad Champagnat (UCH) & 4-Sept-1991 & $586 / 91$ & Mendoza \\
\hline & & & & UP & Universidad FASTA (UfASTA) & 16-Ago-1991 & $456 / 91$ & $\begin{array}{l}\text { Mar del Plata, Buenos } \\
\text { Aires }\end{array}$ \\
\hline & & & & UP & Universidad Blas Pascal (UBP) & 21-Dic-1990 & $2358 / 90$ & Córdoba \\
\hline & & & & UP & Universidad Maimónides & 21-Jun-1990 & $1097 / 90$ & $\begin{array}{l}\text { Ciudad Autónoma de } \\
\text { Bs. As. }\end{array}$ \\
\hline & & & & UN & $\begin{array}{l}\text { Universidad Nacional de La Matanza } \\
\text { (UNLAM) }\end{array}$ & 29-Sept-1989 & 23.748 & $\begin{array}{l}\text { La Matanza, Buenos } \\
\text { Aires }\end{array}$ \\
\hline & & & & UN & $\begin{array}{l}\text { Universidad Nacional de Quilmes } \\
\text { (UNQUI) }\end{array}$ & 29-Sept-1989 & 23.749 & $\begin{array}{l}\text { Bernal (Quilmes) } \\
\text { Buenos Aires }\end{array}$ \\
\hline $\mathbb{S}$ & $\mathrm{R}$ & 1983-1989 & Alfonsin, Raúl Ricardo & UN & $\begin{array}{l}\text { Universidad Nacional de Formosa } \\
\text { (UNF) }\end{array}$ & 24-Sept-1988 & 23.631 & Formosa \\
\hline
\end{tabular}


Universidad

Universidad de San Andrés (UDESA)

Universidad de Palermo (UP)

1982-1983 Bignone, Reynaldo B.

1981-1982 Galtieri, Leopoldo F.

1981-1981 Viola, Roberto E.

1976-1981 Videla, Jorge Rafael

UN

1974-1976 Martínez de Perón, M. E. UN

UN

UN

1973-1974 Perón, Juan Domingo Juan Bosco (UNPSJB (UNMDP)

Universidad Nacional del Centro

(UNICEN)

Universidad de la Marina Mercante (UDEMM)

UN

12-Nov-1986 2357/90

San Fernando, Buenos Aires

Ciudad Autónoma de Bs. As.

Comodoro Rivadavia Chubut

Universidad Nacional de Mar del Plata $\quad$ 27-Oct-1975 21.139

9-Oct-1974 20.753

Mar del Plata, Buenos

Aires

Universidad Nacional de Jujuy (UNJU)

Universidad Nacional de Santiago del Estero (UNSE)

Universidad Nacional de San Juan (UNS)

Universidad Nacional de Entre Ríos (UNER)

Universidad Nacional de San Luis (UNSL)

Universidad Nacional de Misiones (UNM)

Universidad Nacional de La Pampa (UNLPAM)
18-Sept-1974 1870/94

13-Nov-1973 20.579

16-May-1973 20.364

10-May-1973 20.367

10-May-1973 20.366

10-May-1973 20.365

$16-A b r-1973 \quad 20.286$

12-Abr-1973 20.275
Tandil, Buenos Aires

Ciudad Autónoma de

Bs. As.

San Salvador, Jujuy

Santiago del Estero

San Juan, San Juan

Entre Ríos

San Luis, San Luis

Posadas, Misiones

Santa Rosa, La Pampa 


\begin{tabular}{|c|c|c|c|c|c|c|c|c|}
\hline Gobierno & Presidencia & Año & Presidente & Universidad & Institución & Fecha & Ley/Decreto & Provincia \\
\hline & & & & UN & Universidad Nacional de Luján (UNLU) & 20-Dic-1972 & 20.031 & Luján, Buenos Aires \\
\hline $\mathbb{S}$ & $\mathrm{N}$ & 1973-1973 & Lastiri, Raúl Alberto & & & & & \\
\hline $\mathbb{S}$ & $\mathrm{R}$ & 1973-1973 & Campora, Héctor José & & & & & \\
\hline \multirow[t]{6}{*}{ व } & $\mathrm{N}$ & 1971-1973 & Lanusse, Alejandro & UN & $\begin{array}{l}\text { Universidad Nacional de Lomas de } \\
\text { Zamora (UNLZ) }\end{array}$ & 13-Oct-1972 & 19.888 & $\begin{array}{l}\text { Lomas de Zamora, } \\
\text { Bs. As. }\end{array}$ \\
\hline & & & & UN & $\begin{array}{l}\text { Universidad Nacional de Catamarca } \\
\text { (UNCA) }\end{array}$ & 12-Sept-1972 & 19.831 & $\begin{array}{l}\text { San Fernando del } \\
\text { Valle de Catamarca, } \\
\text { Catamarca }\end{array}$ \\
\hline & & & & UN & Universidad Nacional de Salta (UNSA) & 11-May-1972 & 19.633 & Ciudad de Salta, Salta \\
\hline & & & & UN & $\begin{array}{l}\text { Universidad Nacional del Comahue } \\
\text { (UnCOMA) }\end{array}$ & 15-Jul-1971 & 19.117 & $\begin{array}{l}\text { Chubut, Neuquén, } \\
\text { Río Negro }\end{array}$ \\
\hline & & & & UN & $\begin{array}{l}\text { Universidad de Concepción del Uru- } \\
\text { guay (UCU) }\end{array}$ & 20-May-1971 & $1305 / 71$ & $\begin{array}{l}\text { Concepción, Entre } \\
\text { Ríos }\end{array}$ \\
\hline & & & & UN & $\begin{array}{l}\text { Universidad Nacional de Río Cuarto } \\
\text { (UNRC) }\end{array}$ & 1-May-1971 & 19.020 & Río Cuarto, Córdoba \\
\hline 9 & & 1970-1971 & Levingston, Roberto & & & & & \\
\hline \multirow[t]{2}{*}{ ब } & $\mathrm{R}$ & $1966-1970$ & Ongania, Juan Carlos & UN & Universidad Nacional de Rosario (UNR) & 29-Nov-1968 & 17.987 & Rosario, Santa Fe \\
\hline & & & & UP & Universidad CAECE (CAECE) & 20-Sept-1967 & $2435 / 68$ & $\begin{array}{l}\text { Ciudad Autónoma de } \\
\text { Bs. As. }\end{array}$ \\
\hline \multirow[t]{5}{*}{$\mathbb{S}$} & $\mathrm{D}$ & 1963-1966 & Illia, Arturo Humberto & UP & $\begin{array}{l}\text { Universidad del Norte Santo Tomás de } \\
\text { Aquino (UNSTA) }\end{array}$ & 6-Ago-1965 & $6257 / 65$ & $\begin{array}{l}\text { San Miguel de } \\
\text { Tucumán }\end{array}$ \\
\hline & & & & UP & Universidad del Aconcagua (UDA) & 17-May-1965 & $2227 / 73$ & Mendoza \\
\hline & & & & UP & $\begin{array}{l}\text { Universidad Argentina John F. Ken- } \\
\text { nedy (UK) }\end{array}$ & 4-Abr-1964 & $2227 / 68$ & $\begin{array}{l}\text { Ciudad Autónoma de } \\
\text { Bs. As. }\end{array}$ \\
\hline & & & & UP & $\begin{array}{l}\text { Universidad Católica de La Plata } \\
\text { (UCALP) }\end{array}$ & 7-Mar-1964 & $2949 / 71$ & La Plata, Buenos Aires \\
\hline & & & & UP & Universidad de Belgrano (บв) & 11-Sept-1964 & $/ 70$ & $\begin{array}{l}\text { Ciudad Autónoma de } \\
\text { Bs. As. }\end{array}$ \\
\hline
\end{tabular}




\begin{tabular}{|c|c|c|c|c|c|c|c|c|}
\hline Gobierno & Presidencia & Año & Presidente & Universidad & Institución & Fecha & Ley/Decreto & Provincia \\
\hline $\mathbb{S}$ & $\mathrm{N}$ & $1962-1963$ & Guido, José María & UP & Universidad Católica de Salta (UCASAL) & 19-Mar-1963 & $4290 / 64$ & Ciudad de Salta, Salta \\
\hline \multirow[t]{6}{*}{$\mathbb{S}$} & $\mathrm{D}$ & $1958-1962$ & Frondizi, Arturo & UP & Universidad Notarial Argentina (UNA) & 8-May-1962 & $2227 / 68$ & $\begin{array}{l}\text { Ciudad Autónoma de } \\
\text { Bs. As. }\end{array}$ \\
\hline & & & & UP & $\begin{array}{l}\text { Universidad Católica de Santiago del } \\
\text { Estero (UCSE) }\end{array}$ & 21-Jun-1960 & $1960 / 61$ & Santiago del Estero \\
\hline & & & & UP & Universidad de Morón (UNIMORON) & 18-May-1960 & $2227 / 68$ & Morón, Buenos Aires \\
\hline & & & & UP & $\begin{array}{l}\text { Universidad Juan Agustín Maza } \\
\text { (UMAZA) }\end{array}$ & 4-May-1960 & $2152 / 63$ & Mendoza \\
\hline & & & & UP & Universidad de Mendoza (UM) & 13-Mar-1960 & $14179 / 62$ & Mendoza \\
\hline & & & & UP & $\begin{array}{l}\text { Instituto Tecnológico de Buenos Aires } \\
\text { (ITBA) }\end{array}$ & 20-Nov-1959 & $710 / 60$ & $\begin{array}{l}\text { Ciudad Autónoma de } \\
\text { Bs. As. }\end{array}$ \\
\hline \multirow[t]{8}{*}{ T } & $\mathrm{N}$ & 1955-1958 & Aramburu, Pedro E. & UP & Universidad Católica Argentina (UCA) & 7-Mar-1958 & $11911 / 59$ & $\begin{array}{l}\text { Ciudad Autónoma de } \\
\text { Bs. As. }\end{array}$ \\
\hline & & & & UP & $\begin{array}{l}\text { Universidad Católica de Santa Fe } \\
\text { (UCSF) }\end{array}$ & 9-Jun-1957 & $11647 / 58$ & Rosario, Santa Fe \\
\hline & & & & UN & $\begin{array}{l}\text { Universidad Nacional del Nordeste } \\
\text { (UNNE) }\end{array}$ & 14-Dic-1956 & 22.299 & Corrientes \\
\hline & & & & UP & $\begin{array}{l}\text { Universidad Argentina de la Empresa } \\
\text { (UADE) }\end{array}$ & 5-Dic-1956 & $3825 / 72$ & $\begin{array}{l}\text { Ciudad Autónoma de } \\
\text { Bs. As. }\end{array}$ \\
\hline & & & & UP & $\begin{array}{l}\text { Universidad del Museo Social Argenti- } \\
\text { no (UMSA) }\end{array}$ & 5-Nov-1956 & $6403 / 55$ & $\begin{array}{l}\text { Ciudad Autónoma de } \\
\text { Bs. As. }\end{array}$ \\
\hline & & & & UP & Universidad Católica de Córdoba (UCC) & 8-Jun-1956 & $4851 / 59$ & Córdoba \\
\hline & & & & UP & Universidad del Salvador (USAL) & 2-May-1956 & $16365 / 59$ & $\begin{array}{l}\text { Ciudad Autónoma de } \\
\text { Bs. As. }\end{array}$ \\
\hline & & & & UN & Universidad Nacional del Sur (UNS) & 5-Ene-1956 & $154 / 56$ & $\begin{array}{l}\text { Bahía Blanca, Buenos } \\
\text { Aires }\end{array}$ \\
\hline
\end{tabular}




\begin{tabular}{|c|c|c|c|c|c|c|c|c|}
\hline Gobierno & Presidencia & Año & Presidente & Universidad & Institución & Fecha & Ley/Decreto & Provincia \\
\hline $\mathbb{S}$ & $\mathrm{D}$ & 1951-1955 & Perón, Juan Domingo & UP & $\begin{array}{l}\text { Universidad Católica de Cuyo } \\
\text { (uccuyo) }\end{array}$ & 12-Jul-1963 & $14557 / 63$ & $\begin{array}{l}\text { San Juan, San Luis, } \\
\text { Mendoza }\end{array}$ \\
\hline $\mathbb{S}$ & $\mathrm{C}$ & $1946-1951$ & Perón, Juan Domingo & UN & $\begin{array}{l}\text { Universidad Tecnológica Nacional } \\
\text { (UTN) }\end{array}$ & 19-Ago-1948 & 13.229 & $\begin{array}{l}\text { Ciudad Autónoma de } \\
\text { Bs. As. }\end{array}$ \\
\hline T & $\mathrm{N}$ & $1944-1946$ & Farrell, Edelmiro & & & & & \\
\hline ब & $\mathrm{D}$ & 1943-1944 & Ramírez, Pedro Pablo & & & & & \\
\hline $\mathbb{S}$ & $\mathrm{D}$ & $1942-1943$ & Castillo, Ramón S. & & & & & \\
\hline $\mathbb{S}$ & $\mathrm{R}$ & 1938-1942 & Ortiz, Roberto M. & UN & $\begin{array}{l}\text { Universidad Nacional de Cuyo } \\
\text { (UnCUYo) }\end{array}$ & 21-Mar-1939 & 26.971 & Mendoza \\
\hline $\mathbb{S}$ & $\mathrm{C}$ & $1932-1938$ & Justo, Agustín P. & & & & & \\
\hline 9 & $\mathrm{N}$ & 1930-1932 & Uriburu, José Félix & & & & & \\
\hline $\mathbb{S}$ & $\mathrm{D}$ & $1928-1930$ & Yrigoyen, Hipólito & & & & & \\
\hline $\mathbb{S}$ & $\mathrm{C}$ & $1922-1928$ & de Alvear, Marcelo T. & & & & & \\
\hline $\mathbb{S}$ & $\mathrm{C}$ & $1916-1922$ & Yrigoyen, Hipólito & & & & & \\
\hline $\mathbb{S}$ & $\mathrm{C}$ & 1914-1916 & de la Plaza, Victorino & & & & & \\
\hline $\mathbb{S}$ & $\mathrm{F}$ & 1910-1914 & Saenz Peña, Roque & UN & $\begin{array}{l}\text { Universidad Nacional de Tucumán } \\
\text { (UNT) }\end{array}$ & 25-May-1914 & 11.027 & $\begin{array}{l}\text { S. Miguel Tucumán, } \\
\text { Tucumán }\end{array}$ \\
\hline $\mathbb{S}$ & $\mathrm{C}$ & $1906-1910$ & Figueroa Alcorta, José & & & & & \\
\hline $\mathbb{S}$ & $\mathrm{F}$ & $1904-1906$ & Quintana, Manuel & & & & & \\
\hline $\mathbb{S}$ & $\mathrm{C}$ & 1898-1904 & Roca, Julio Argentino & & & & & \\
\hline $\mathbb{S}$ & $\mathrm{C}$ & $1895-1898$ & Uriburu, José E. & UN & $\begin{array}{l}\text { Universidad Nacional de La Plata } \\
\text { (UNLP) }\end{array}$ & 18-Abr-1897 & 4.699 & La Plata, Bs. As. \\
\hline $\mathbb{S}$ & $\mathrm{R}$ & $1892-1895$ & Saenz Peña, Luis & & & & & \\
\hline $\mathbb{S}$ & $\mathrm{C}$ & $1890-1892$ & Pellegrini, Carlos & & & & & \\
\hline $\mathbb{S}$ & $\mathrm{R}$ & $1886-1890$ & Juárez Celman, Miguel & UN & Universidad Nacional del Litoral (UNL) & 16-Oct-1889 & 10.861 & Sta. Fe, Santa Fe \\
\hline $\mathbb{S}$ & $\mathrm{C}$ & $1880-1886$ & Roca, Julio Argentino & & & & & \\
\hline $\mathbb{S}$ & $\mathrm{C}$ & $1874-1880$ & Avellaneda, Nicolás & & & & & \\
\hline $\mathbb{S}$ & $\mathrm{C}$ & $1868-1874$ & Sarmeinto, Domingo F. & & & & & \\
\hline
\end{tabular}




\begin{tabular}{|c|c|c|c|c|c|c|c|c|}
\hline Gobierno & Presidencia & Año & Presidente & Universidad & Institución & Fecha & Ley/Decreto & Provincia \\
\hline $\mathbb{S}$ & $\mathrm{C}$ & $1862-1868$ & Mitre, Bartolomé & & & & & \\
\hline $\mathbb{S}$ & $\mathrm{C}$ & $1861-1862$ & Pedernera, Juan Esteban & & & & & \\
\hline $\mathbb{S}$ & $\mathrm{R}$ & $1860-1861$ & Derqui, Santiago & & & & & \\
\hline $\mathbb{S}$ & $\mathrm{C}$ & $1854-1860$ & de Urquiza, Justo José & & & & & \\
\hline $\mathbb{S}$ & $\mathrm{C}$ & $1852-1854$ & de Urquiza, Justo José & & & & & \\
\hline $\mathbb{S}$ & $\mathrm{C}$ & $1852-1852$ & López y Planes, Vicente & & & & & \\
\hline $\mathbb{S}$ & $\mathrm{C}$ & $1835-1852$ & de Rosas, Juan Manuel & & & & & \\
\hline $\mathbb{S}$ & $\mathrm{C}$ & $1834-1835$ & Maza, Manuel Vicente & & & & & \\
\hline $\mathbb{S}$ & $\mathrm{C}$ & $1833-1834$ & Viamonte, Juan José & & & & & \\
\hline $\mathbb{S}$ & $\mathrm{C}$ & $1832-1833$ & Glez Balcarce, J. Ramón & & & & & \\
\hline $\mathbb{S}$ & $\mathrm{C}$ & $1929-1932$ & de Rosas, Juan Manuel & & & & & \\
\hline $\mathbb{S}$ & $\mathrm{C}$ & 1929-1929 & Viamonte, Juan José & & & & & \\
\hline $\mathbb{S}$ & $\mathrm{C}$ & $1828-1829$ & Lavalle, Juan Galo & & & & & \\
\hline $\mathbb{S}$ & $\mathrm{C}$ & $1827-1828$ & Dorrego, Manuel & & & & & \\
\hline $\mathbb{S}$ & $\mathrm{C}$ & $1827-1827$ & López y Planes, Vicente & & & & & \\
\hline \multirow[t]{9}{*}{$\mathbb{S}$} & $\mathrm{R}$ & $1826-1827$ & Rivadavia, Bernardino & & & & & \\
\hline & $\mathrm{C}$ & $1820-1826$ & Autonomías Provinciales & UN & Universidad de Buenos Aires (UBA) & 12-Ago-1821 & edicto & $\begin{array}{l}\text { Ciudad Autónoma de } \\
\text { Bs. As. }\end{array}$ \\
\hline & $\mathrm{C}$ & $1815-1820$ & $\begin{array}{l}\text { Directorio (Asamblea } \\
\text { año XIII) }\end{array}$ & & & & & \\
\hline & $\mathrm{C}$ & $1815-1815$ & Tercer Triunvirato & & & & & \\
\hline & $\mathrm{C}$ & $1812-1814$ & Segundo Triunvirato & & & & & \\
\hline & $\mathrm{C}$ & $1811-1811$ & Primer Triunvirato & & & & & \\
\hline & $\mathrm{C}$ & $1811-1811$ & Matheu, Domingo & & & & & \\
\hline & $\mathrm{C}$ & $1810-1811$ & Saavedra, Cornelio & & & & & \\
\hline & $\mathrm{C}$ & $1776-1810$ & $\begin{array}{l}\text { Virreinato del Río de La } \\
\text { Plata }\end{array}$ & & & & & \\
\hline
\end{tabular}




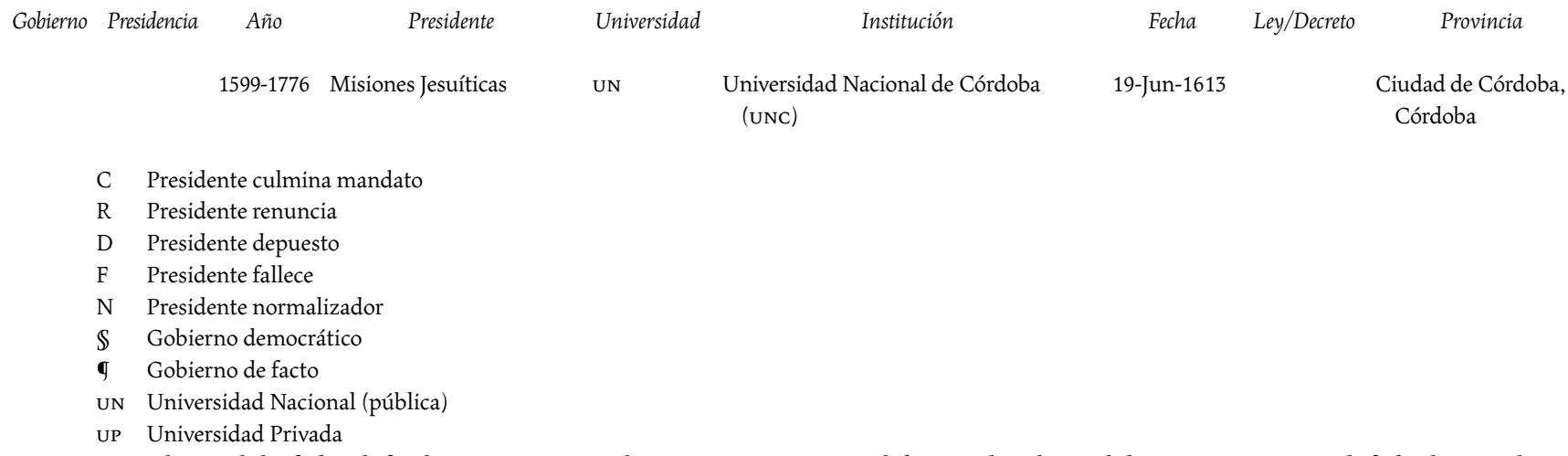
C Presidente culmina mandato
D Presidente depuesto
UP Universidad Privada

$\mathrm{R}$ Presidente renuncia

F Presidente fallece

N Presidente normalizador

S Gobierno democrático

I Gobierno de facto

UN Universidad Nacional (pública)

Nota: algunas de las fechas de fundación se remontan a los primeros momentos en la historia de cada una de las instituciones y no a la fecha de promulgación de la ley (en las universidades nacionales) o del decreto/resolución ministerial (en el caso de las universidades privadas).

Usualmente la fecha fundacional no coincide con el año de promulgación de la Ley del Poder Legislativo o Decreto del Poder Ejecutivo debido a la complejidad del proceso de regulación.

Las ciudades/provincias que figuran responden en la mayoría de los casos a la ciudad donde radica la sede central. 